\section{Pacific Northwest}

National Laboratory

Operated by Battelle for the

U.S. Department of Energy

\title{
FY 2006 Infrared Photonics Final Report
}

\author{
N. C. Anheier \\ P. J. Allen \\ B. E. Bernacki \\ N. Hô \\ K. Krishnaswami \\ A. Qiao \\ J. F. Schultz
}

December 2006

Prepared for the U.S. Department of Energy under Contract DE-AC05-76RL01830 


\section{FY 2006 Infrared Photonics Final Report}

N. C. Anheier

P. J. Allen

Bruce Bernacki

Nicolas Hô

Kannan Krishnaswami

A. Qiao

J. F. Schultz

December 2006

Prepared for

the U.S. Department of Energy

under Contract DE-AC05-76RLO1830

Pacific Northwest National Laboratory

Richland, Washington 99352 



\section{Summary}

Research done by the Infrared Photonics team at Pacific Northwest National Laboratory (PNNL) is focused on developing miniaturized integrated optics and optical fiber processing methods for mid-wave infrared (MWIR) and long-wave infrared (LWIR) sensing applications by exploiting the unique optical and material properties of chalcogenide glass. PNNL has developed thin-film deposition capabilities, direct laser writing techniques, infrared photonic device demonstration, holographic optical element design and fabrication, photonic device modeling, and advanced optical metrology—all specific to chalcogenide glass. Chalcogenide infrared photonics provides a pathway to quantum cascade laser (QCL) transmitter miniaturization. The high output power, small size, and superb stability and modulation characteristics of QCLs make them amenable for integration as transmitters into ultra-sensitive, ultraselective point sampling and remote short-range chemical sensors that are particularly useful for nuclear nonproliferation missions.

During FY 2006, PNNL's Infrared Photonics research team made measurable progress exploiting the extraordinary optical and material properties of chalcogenide glass to develop miniaturized integrated photonic components. The culmination of this development effort led to the first reported demonstration of a MWIR single-mode waveguide in chalcogenide glass coupled to a QCL source. Improvements were made to the chalcogenide glass thin film deposition system, including the installation of a 192 square foot, Class 10,000 clean room. It is anticipated that these improvements will lead to the routine production of low-loss, optical-quality chalcogenide thin films required for the photonic component development effort. Traditional and direct-write lithography processes were developed for chalcogenide glass that will provide the capability to fabricate etched ridge waveguide structures with index modulation provided by direct-laser written Bragg grating structures. Chalcogenide optical fiber processing methods are being developed using a Vytran large core optical fiber fusion splicer. This work will provide a unique capability to process infrared optical fibers to produce tapered QCL laser couplers, fiber splitters and combiners, and fiber-to-fiber fusion splicing. Custom asphere lens designs were developed to efficiently collect the highly divergent QCL emission and refocus into both chalcogenide optical fibers and thin-film waveguides. These lenses were sent offsite for fabrication using single-point diamond turning methods and then characterized using the suite of LWIR optical metrology tools developed at PNNL.

The Infrared Photonics research is positioned to develop chalcogenide-based infrared photonic components such as waveguides, beam splitters, multiplexers, couplers, beam shapers, Bragg reflectors, long-period gratings, hybrid lenses, and optical fibers. The integration of these photonic components and optical fibers along with the QCL source will provide a compact laser transmitter, meeting the needs for a variety of infrared sensing missions. 


\section{Contents}

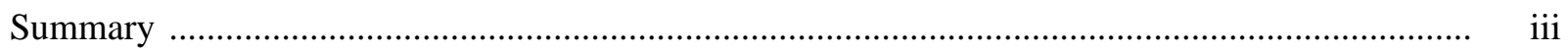

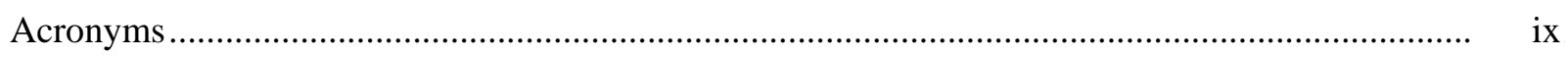

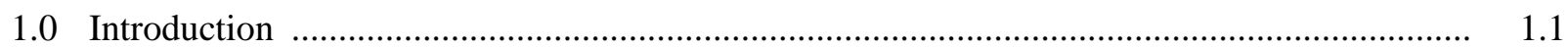

2.0 Chalcogenide Thin Film Deposition Research ............................................................. 2.1

2.1 Thin Film Deposition System ……......................................................................... 2.1

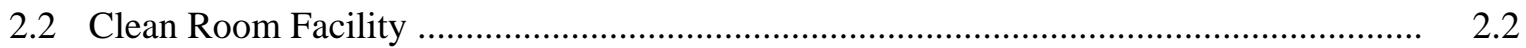

3.0 Chalcogenide Photonic Device Research ...................................................................

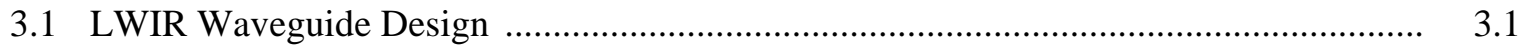

3.2 LWIR Waveguide Fabrication and Performance ….................................................... 3.2

3.3 LWIR Optical Fiber Research ............................................................................... 3.4

3.4 QC Laser Fiber Coupling Experiments ................................................................... 3.5

4.0 Fabrication of Etched Chalcogenide Waveguides ............................................................... 4.1

4.1 Simulation of Etched Waveguides .................................................................................. 4.1

4.2 Etching $\mathrm{As}_{2} \mathrm{Se}_{3}$ with Ethanolamine .......................................................................... 4.2

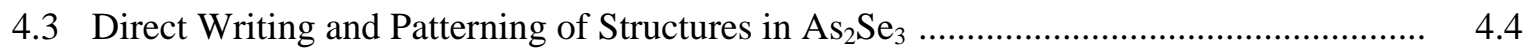

4.4 Next Phase in $\mathrm{As}_{2} \mathrm{Se}_{3} W$ aveguide Fabrication ............................................................ 4.5

5.0 QC Laser Optical Design .................................................................................... 5.1

5.1 Collimation Lens Design - Variant 1 ......................................................................... 5.1

5.2 Collimation Lens Design - Variant 2 ....................................................................... 5.2

5.3 Mid-IR Optical Fiber and Waveguide Coupling Lenses............................................. 5.5

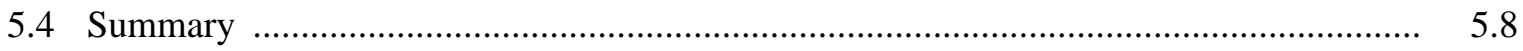

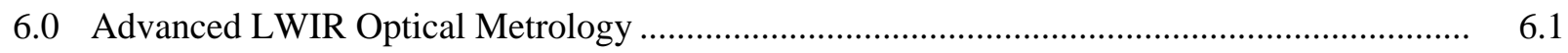

6.1 QCL Beam Divergence Characterization......................................................................... 6.1

6.2 Germanium Asphere Lens Characterization .................................................................. 6.3

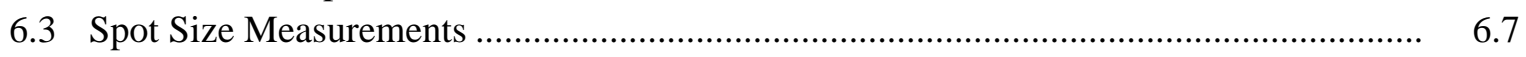

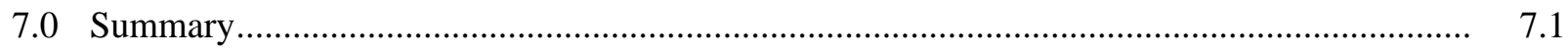

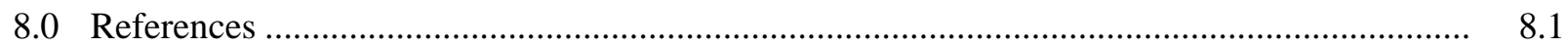




\section{Figures}

2.1 Chalcogenide Thin Film Deposition System

2.2 Improved Sample Holder Fixture

2.3 Airborne Dust and Organic Compound Contamination

3.1 Channel Waveguide Design

3.2 SEM Cross Section of Multilayer Film

3.3 Intensity Distribution at the Output of the Waveguides

3.4 Fabrication of Waveguide Couplers.

3.5 Output Power Distribution of an Array of Widely Spaced Waveguides

3.6 QCL Fiber-Coupling Experiments

3.7 Mid-IR Fiber Output Mode Measurements .....

4.1 Simulated Mode Profiles for a Ridge Thickness of $0.5 \mu \mathrm{m}$

4.2 Simulated Mode Profiles for a Ridge Thickness of $1.0 \mu \mathrm{m}$

4.3 Step Heights of $\mathrm{As}_{2} \mathrm{Se}_{3}$ as a Function of Etch Time in Ethanolamine at $23^{\circ} \mathrm{C}$.....

4.4 Step Heights of $\mathrm{As}_{2} \mathrm{Se}_{3}$ as a Function of Etch Time in Ethanolamine at $23^{\circ} \mathrm{C}$ with Initial Data Points Removed to Correct for Surface Layer

4.5 Step Height Measurements of a Direct Write Process Using Ultraviolet Flood Lamp and Ethanolamine Etch

4.6 Step Height Measurements of a Direct Write Process Using an Argon Laser and Ethanolamine Etch.

5.1 Divergence Plots Showing the Fast and Slow Axes Intensity Profiles for a Room Temperature QCL

5.2 The 0.85 NA Lens System Summary Showing the 2D Optical Layout, RMS vs. WFE Plot, Longitudinal Aberration Plot and Modulation Transfer Function 
5.4 System Summary Graphic for the 0.3 NA Lens Showing Diffraction-Limited

Performance for Field Heights up to $\pm 500 \mu \mathrm{m}$

5.5 System Summary Graphic for the 0.6 NA Germanium Coupling Lens ............................... 5.7

5.6 A System Summary Graphic of the 0.8 NA Plano Convex Germanium Lens Designed for Photonics Research

6.1 Typical Emission Profile of a QCL along the Fast and Slow Axes with the Presence of Fringing Superposed on the Fast Axis

6.2 Fast Axis Fringing Occurs When a QCL Die is Set Back from the Edge of the C Mount Causing Reflections from the Lip and Clipping from the Edge

6.3 Typical Emission Profile of a QCL along the Fast and Slow Axes with Reduced Fast Axis Fringing

6.4 Schematic of a LWIR Twyman-Green Interferometer to Measure Wavefront Aberrations in Custom Aspheres

6.5 Screen Capture of the Fringe Analysis for a 0.85NA Ge Asphere Designed to Collimate QCLs....

6.6 Screen Capture of the Fringe Analysis for a 25-mm Focal Length Ge Asphere Designed for Focusing the QCL Beam.

6.7 Statistical Distribution of Spherical Aberration Measured in $25 \mathrm{~mm}$ Focal Length

Germanium Aspheres Designed for Focusing the QCL Beam

6.8 Spot Size Data Measured at Various Locations within the Focal Region

6.9 Spot Size Data Measured at Focus for Slow Axis and Fast Axis

\section{Tables}

5.1 Summary of Design Parameters for the 0.85 NA Collimating Lens

5.2 Lens Parameter Summary for the Second Collimating Lens Variant.

5.3 Summary of the Design Parameters for the Three Plano-Convex Germanium Lenses Design for General Purpose Waveguide and Fiber Research. 
6.1 Performance Characteristics for Custom-Made Collimating and Focusing

Lenses for Waveguide Coupling and Chemical Sensing Applications......................................

6.7

6.2 Performance Characteristics for Custom-Made Waveguide-Coupling Lenses ........................ 6.7 


\section{Acronyms}

$\begin{array}{ll}\text { LWIR } & \begin{array}{l}\text { long-wave infrared } \\ \text { MTF }\end{array} \\ \text { MWIR } & \begin{array}{l}\text { modulation transfer function } \\ \text { mid-wave infrared }\end{array} \\ \text { PNNL } & \text { Pacific Northwest National Laboratory } \\ \text { QCL } & \text { quantum cascade laser } \\ \text { SEM } & \text { scanning electron microscope } \\ \text { TE } & \text { transverse electric } \\ \text { TM } & \text { transverse magnetic } \\ \text { WFE } & \text { Wave Front Error }\end{array}$




\subsection{Introduction}

The goal of PNNL's Infrared Photonics Project is to develop innovative infrared technologies that will enable a new line of compact, field-deployable chemical sensing systems designed specifically for proliferation detection. Chalcogenide glasses are attractive materials for fabricating mid-wave infrared (MWIR) and long-wave infrared (LWIR) photonic components because they exhibit relatively low transmission losses in combination with unique photomodification properties. Amorphous chalcogenide glasses exhibit a number of unique phase change properties when illuminated by near band-gap photon energies. One of these transformations is photodarkening, which corresponds to a photo-induced red shift of the absorption spectrum. For photon energy below the band-gap energy, this shift leads to an increase in refractive index. It is thus possible to exploit this effect in a controlled manner to create waveguides and associated photonic structures patterned directly in the glass by either using a write-beam or by flood exposing the glass through an amplitude or phase mask. Using these properties PNNL is developing photonic components that are essential to the miniaturization of infrared sensing systems. In addition to thin film devices, PNNL is also developing novel chalcogenide optical fiber processing techniques to produce fiber tapers, fused core fiber couplers, fused lenses to fibers and lensed fibers, all essential to the miniaturization of an MWIR or LWIR QCL transmitter compatible with field-portable chemical sensing platforms.

In this report we provide a summary of the FY 2006 research progress for the Infrared Photonics project, a subtask under the ITAS program (PL211i). Background information on PNNL's chalcogenide infrared photonics research can be found in our previous reports (Anheier et al. 2004, 2005). In Section 2, we provide an update on PNNL's chalcogenide thin film deposition capability and our plans for an expanded clean room facility to improve film quality. In Section 3, we discuss the first reported demonstration of an MWIR single-mode waveguide in chalcogenide glass coupled to a QCL source with additional waveguide and infrared optical fiber developments. In Section 4, we introduce the direct-write capability for fabricating etched ridge waveguide structures in conjunction with photodarkening to create MWIR and LWIR photonic components. In Section 5, we report on the design of high-performance germanium asphere lenses for collimating QCLs and for subsequent waveguide coupling, Section 6 describes the optical metrology performed on both QCL and asphere lenses to quantify their optical performance. 


\subsection{Chalcogenide Thin Film Deposition Research}

Chalcogenide glasses are particularly suited to thermal vacuum evaporation due to their low melting temperatures. Both single-layer $\left(\mathrm{As}_{2} \mathrm{~S}_{3}\right.$ or $\left.\mathrm{As}_{2} \mathrm{Se}_{3}\right)$ and multi-layer $\left(\mathrm{As}_{2} \mathrm{~S}_{3}+\mathrm{As}_{2} \mathrm{Se}_{3}\right)$ chalcogenide film structures were deposited for fabricating laser-written waveguides described in Section 3 and for the lithography/etching study described in Section 4 of this report.

\subsection{Thin Film Deposition System}

Chalcogenide glass amorphous thin films are deposited with a custom thermal vacuum deposition system designed and fabricated for PNNL by the Kurt J. Lesker Company. Bulk compositions of $\mathrm{As}_{2} \mathrm{~S}_{3}$, $\mathrm{As}_{2} \mathrm{Se}_{3}$, and custom glass compositions are routinely deposited using this system. The vacuum deposition system, shown in Figure 2.1, has three independent resistance-heated evaporation sources allowing sequential multi-layered deposition required for fabricating the core and cladding of a waveguide as described later in Section 3. Typically $2 \mu \mathrm{m}$ thick films are simultaneously deposited onto $\mathrm{Si} / \mathrm{SiO}_{2}$ substrates and cleaned microscope slides at a rate of $6 \AA / s$ and at a pressure of $8 \times 10^{-7}$ Torr. The stoichiometry of both the binary and ternary films have been confirmed using electron dispersion spectroscopy, which indicated that the composition was within $2 \%$ of bulk glass stoichiometry.

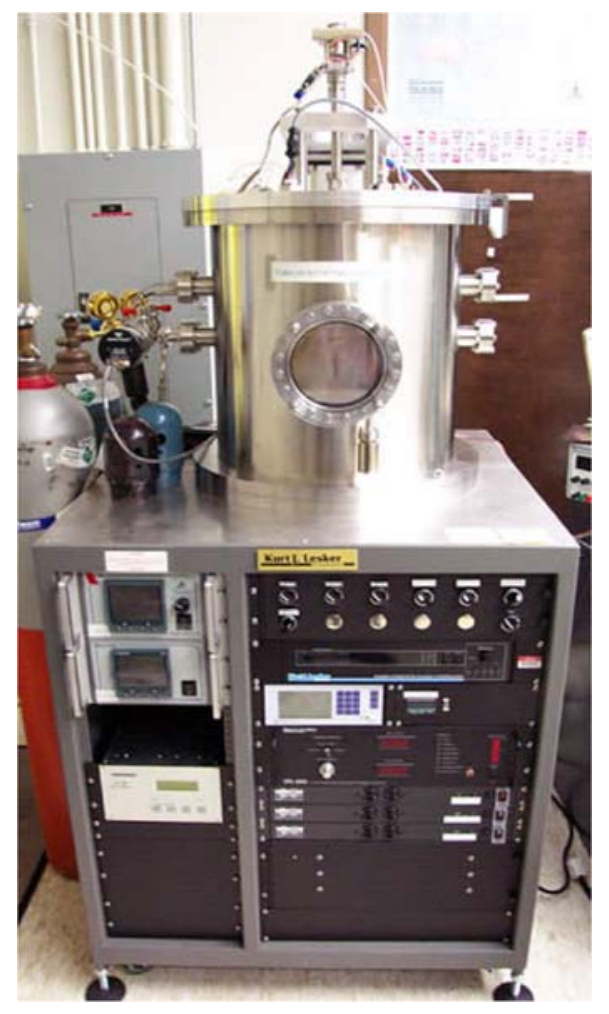

Figure 2.1. Chalcogenide Thin Film Deposition System 
During FY 2006 significant improvements were made in the deposition system. The pumping station was replaced to improve the pump down rate and pressure performance and also to resolve periodic maintenance issues. In addition, a gate valve was installed between the chamber and the turbo pump to prevent venting of the deposition chamber when the turbo pump was de-energized. An added benefit of the gate valve is that it simplifies leak detection.

The rotary sample holder was redesigned to provide eccentric planetary motion to improve thickness uniformity of the deposited films and also to simplify the sample loading and unloading procedure. The new sample holder provides fixtures for both microscope slides and $100-\mathrm{mm} \mathrm{Si} / \mathrm{SiO}_{2}$ wafer substrates, as shown in Figure 2.2. The microscope slides serve as witness samples for the post deposition characterization.

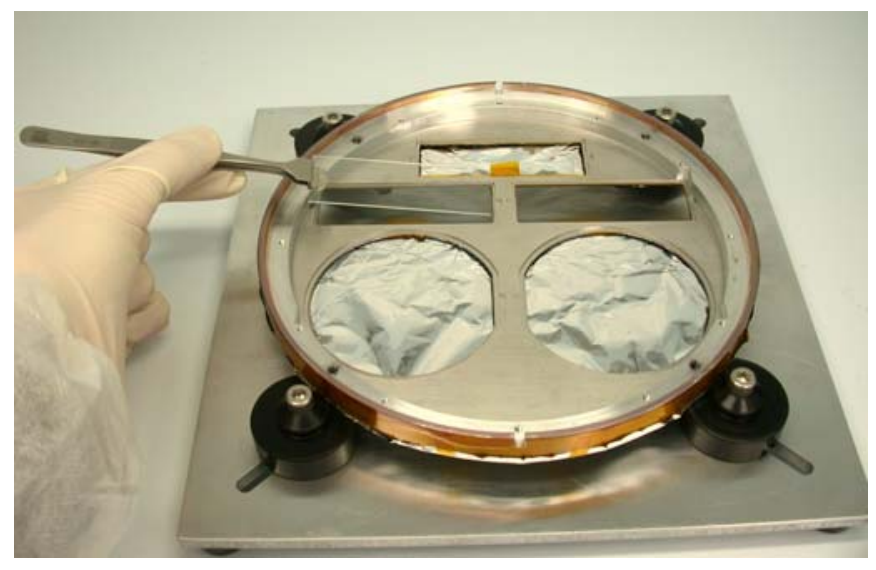

Figure 2.2. Improved Sample Holder Fixture

\subsection{Clean Room Facility}

During the course of many deposition processes, it was routinely identified that airborne dust and organic compounds led to both thin film delamination and reduction in optical performance for fabricated thin film photonic components. Figure 2.3 shows examples of delaminated films and embedded dust particles due to the sample preparation and deposition process in an uncontrolled environment.

During FY 2006 PNNL began developing a clean room facility to mitigate the contamination problems that were impacting the quality of chalcogenide thin films. Laboratory space was remodeled to accommodate a 192 square foot, class 10,000, modular clean room. A custom soft wall modular clean room was specified and procured from Terra Universal. The design included a freestanding metal frame structure with transparent flexible plastic sideways. Ceiling mounted filter/fan units provide a reliable flow of microfiltered air to meet the Class 10,000 specification. This clean room will primarily house the thin film deposition system, a chemical wet bench for sample preparation, and a small vented glove box for sample inspection and loading. The laboratory remodel was completed during FY 2006, but due to fabrication delays, assembly of the modular clean room will occur during the first quarter of FY 2007. 


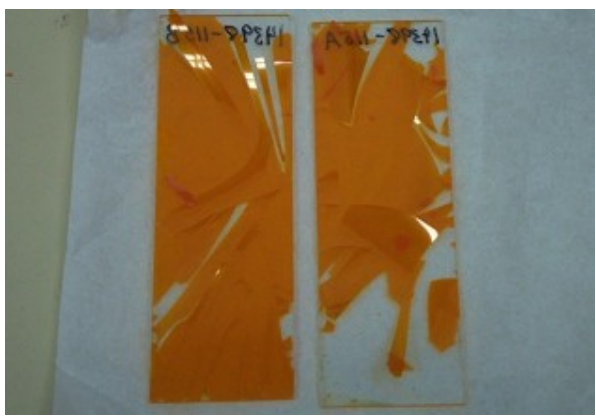

(a)

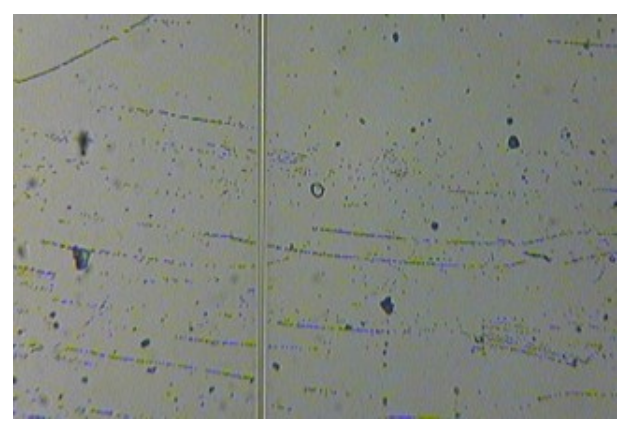

(b)

Figure 2.3. Airborne Dust and Organic Compound Contamination. (a) Thin film delamination and (b) thin film particulate contamination. 
2.4 


\subsection{Chalcogenide Photonic Device Research}

During FY 2006, PNNL designed and fabricated low-loss singlemode waveguides in chalcogenide glass thin films using the direct write technique. The results of this research were presented at the Frontier in Optics conference (Hô et al. 2006a), published in Optics Letters (Hô et al. 2006b), and were the subject of a review article in the trade journal Photonics Spectra (Hitz 2006).

\subsection{LWIR Waveguide Design}

The planar thin-film structure, shown in Figure 3.1, was designed to guide a QCL emitting at $8.4 \mu \mathrm{m}$. $\mathrm{As}_{2} \mathrm{Se}_{3}(n=2.78)$ was used as the waveguide core and $\mathrm{As}_{2} \mathrm{~S}_{3}(n=2.39)$, which has a lower refractive index, was used as a lower cladding layer. The top cladding layer was air. The substrate was an $\mathrm{Si} / \mathrm{SiO}_{2} \mathrm{wafer}$ that provides the possibility of cleaving the sample, thus producing high-quality end faces. Because silicon has a higher refractive index than any glass of the As-S-Se family, a cladding layer of $\mathrm{As}_{2} \mathrm{~S}_{3}$ was necessary to meet the waveguide requirements. The cladding layer was designed to be $\sim 4.5 \mu \mathrm{m}$, thick enough to prevent interaction of the field with the wafer. However, Si substrates with a $2 \mu \mathrm{m} \mathrm{SiO}_{2}$ layer, which is opaque in the MIR, were used to prevent possible coupling from the waveguide into the $\mathrm{Si}$ substrate. Depositing an additional glass cladding layer on top of the core would reduce losses, but achieving such thick films is a major technical challenge that is currently being addressed (see Section 2). As the film layer thickness increases, they tend to break and delaminate due to internal stress.

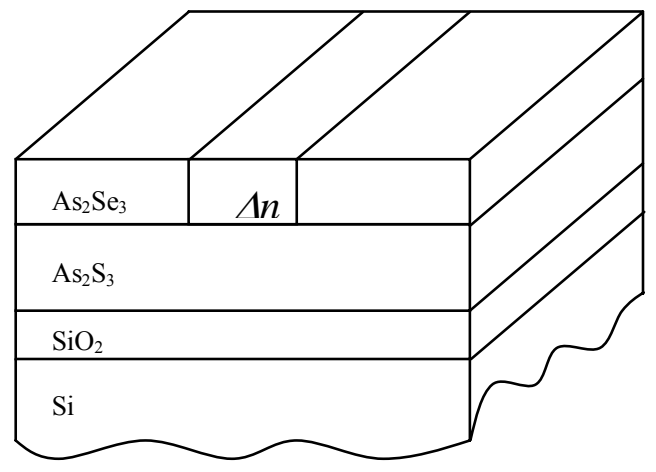

Figure 3.1. Channel Waveguide Design

The index difference between the layers allows confinement of light in the $\mathrm{As}_{2} \mathrm{Se}_{3}$ layer, but an increase of index within this layer itself is necessary to confine light in both dimensions, thus creating a channel waveguide. The photodarkening effect in chalcogenide glasses was exploited using the direct write method. This process of direct writing using a laser with near band-gap wavelength was described in the FY 2005 report (Anheier et al. 2005). 


\subsection{LWIR Waveguide Fabrication and Performance}

Thin films of glass were deposited on a crystalline silicon substrate with an oxide layer $\left(\mathrm{Si} / \mathrm{SiO}_{2}\right)$. $\mathrm{As}_{2} \mathrm{~S}_{3}$ followed by $\mathrm{As}_{2} \mathrm{Se}_{3}$ was deposited at a rate of 5-10 $\AA / \mathrm{s}$ by thermal evaporation in a vacuum chamber at a base pressure of $4 \times 10^{-6}$ Torr. A substrate holder with planetary motion was used to maintain thickness uniformity within $1 \%$ of the total thickness. The planar structure was cleaved for crosssectional analysis using a scanning electron microscope (SEM). Figure 3.2(a) shows a micrograph of the cross-section of the waveguide layers and its dimensions. The $\mathrm{As}_{2} \mathrm{Se}_{3}$ core layer and $\mathrm{As}_{2} \mathrm{~S}_{3}$ cladding layer were measured to be $3.81 \mu \mathrm{m}$ and $4.53 \mu \mathrm{m}$ thick, respectively. Energy dispersive X-ray spectroscopy confirmed that the stoichiometry of the bulk materials was preserved.

(a)

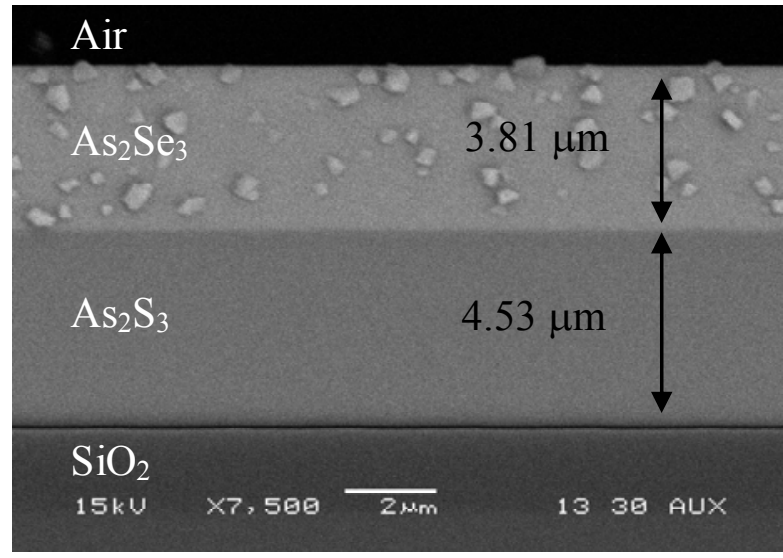

(b)

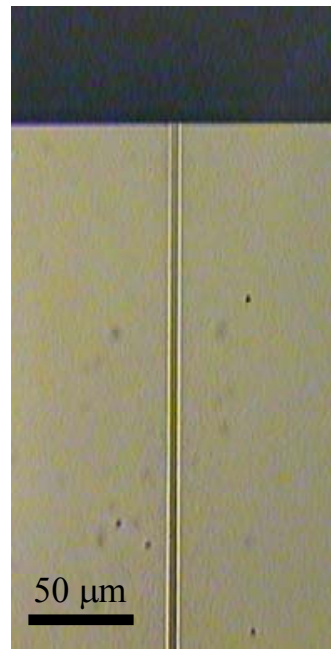

Figure 3.2. SEM Cross Section of Multilayer Film. (a) Cross sectional SEM analysis of the films; (b) Optical microscope image from the top after laser writing, showing the waveguide.

After depositing the waveguide structure, the sample was placed in a laser writing station to record the channel by increasing the local index of refraction. For this, a $633 \mathrm{~nm} H e N e$ laser with a power of $1.0 \mathrm{~mW}$ was focused to a tight spot using an aspheric lens with an effective focal length of $11 \mathrm{~mm}$. As a result, the laser written lines were $5.4 \mu \mathrm{m}$ wide and $5.40 \mathrm{~cm}$ long. Figure 3.2(b) shows a top view image of the fabricated waveguides. These waveguide samples were then cleaved at both ends and their performance characterized.

A QCL emitting at a wavelength of $8.4 \mu \mathrm{m}$ was end-fire coupled using a custom-made ZnSe airspaced doublet of high numerical aperture $(\mathrm{NA}=0.85)$. The output of the waveguide was observed to be singlemode, as shown in Figure 3.3, and changing input conditions did not excite other modes. The output profile showed a good fit with a Gaussian function with a mode diameter $\left(1 / e^{2}\right)$ of $18.1 \mu \mathrm{m}$. 

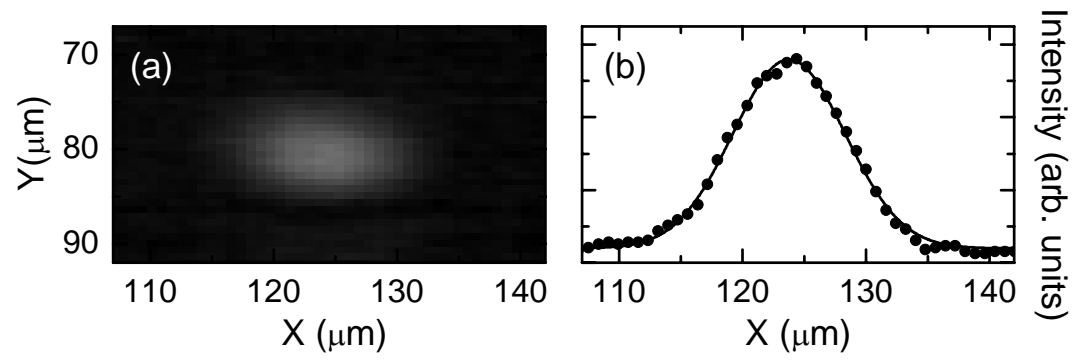

Figure 3.3. Intensity Distribution at the Output of the Waveguides. (a) Mode imaged on a microbolometer array; (b) Intensity distribution in the horizontal axis (points) and Gaussian fit (line).

The propagation losses of the waveguides were measured using a cut-back technique. A series of 10-channel waveguides were recorded within the same multilayer film, initially $3.55 \mathrm{~cm}$ long. The transmission of each waveguide was repeatedly measured after reducing the waveguide length by cleaving the output end. Both transverse electric (TE) and transverse magnetic (TM) transmission were measured for a total of four different lengths and the propagation losses determined from fitting the data to an exponential. The measured average propagation loss was $0.5 \pm 0.1 \mathrm{~dB} / \mathrm{cm}$ for TE polarization and $1.1 \pm 0.1 \mathrm{~dB} / \mathrm{cm}$ for TM polarization. The higher TM losses were as expected for planar waveguide devices.

Losses of $1 \mathrm{~dB} / \mathrm{cm}$ or less are considered low for integrated optics because many functionalities can be located within a small distance. Furthermore, these low values imply that the thickness of the cladding was large enough. Leakage through the cladding results in large losses since the $\mathrm{SiO}_{2}$ layer is extremely absorbent in the mid-IR. Previous experiments with a thinner cladding layer of $2.69 \mu \mathrm{m}$ showed much higher losses of up to $6.5 \pm 0.3 \mathrm{~dB} / \mathrm{cm}$ for TM polarization.

Having measured the propagation losses in the waveguides, we determined the injection efficiency to be approximately $20 \%$, defined as the ratio of optical power before and after the input facet. Due to the large refractive indices of chalcogenide glass, the Fresnel reflections limit the coupling efficiency. Also, no effort was made to optimize mode matching between the input beam and the waveguide. Further improvements in coupling efficiency could be expected from spatially filtering the QCL beam and using cylindrical optics to match the focused beam shape to the waveguide mode dimensions. It is also possible to use a thicker core layer that will still retain the single-mode property and allow larger coupling efficiency. However, as mentioned earlier, thermal deposition of layers greater than $10 \mu \mathrm{m}$ in thickness is challenging and requires careful control of the deposition parameters.

Two other types of waveguide structures were fabricated. First, a waveguide coupler was fabricated by recording two waveguides next to each other. Through evanescent wave interactions, the power from one waveguide can be transferred to the other waveguide. Figure 3.4 shows the fabricated structure and the output profile. Here, the power from a single input was separated in two outputs via evanescent coupling between the two waveguides. 


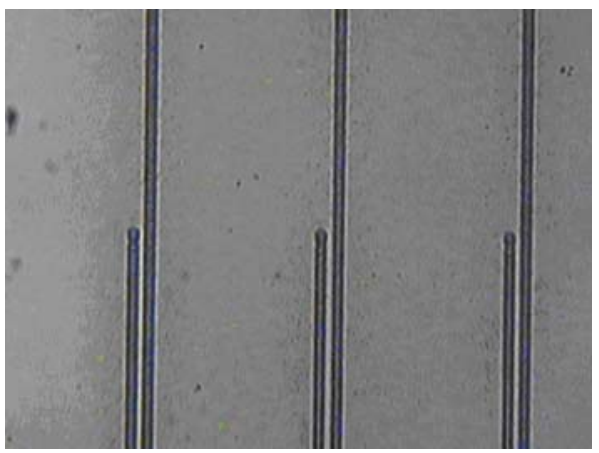

(a)

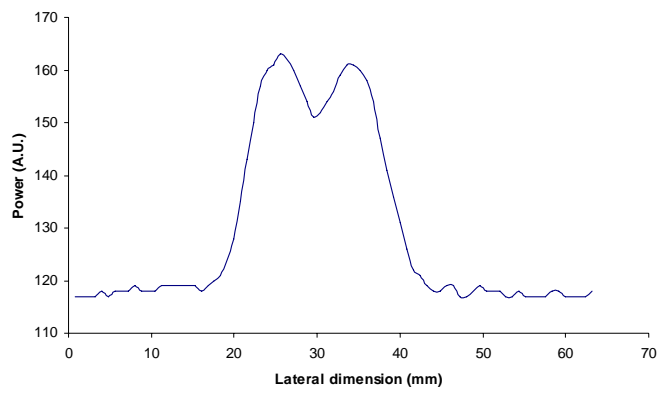

(b)

Figure 3.4. Fabrication of Waveguide Couplers. (a) Three couplers are shown. The single input, from the top of the figure, is split in two outputs. (b) Output of the coupler.

An array of waveguides was also recorded. Instead of laser-writing two waveguides in close proximity, the waveguides were separated from each other by $100 \mu \mathrm{m}$. Figure 3.5 shows that the longer QCL emission wavelength leads to very large modes that interact with other waveguides over great distances. This effect is very important and needs to be considered when designing mid-IR waveguide structures.

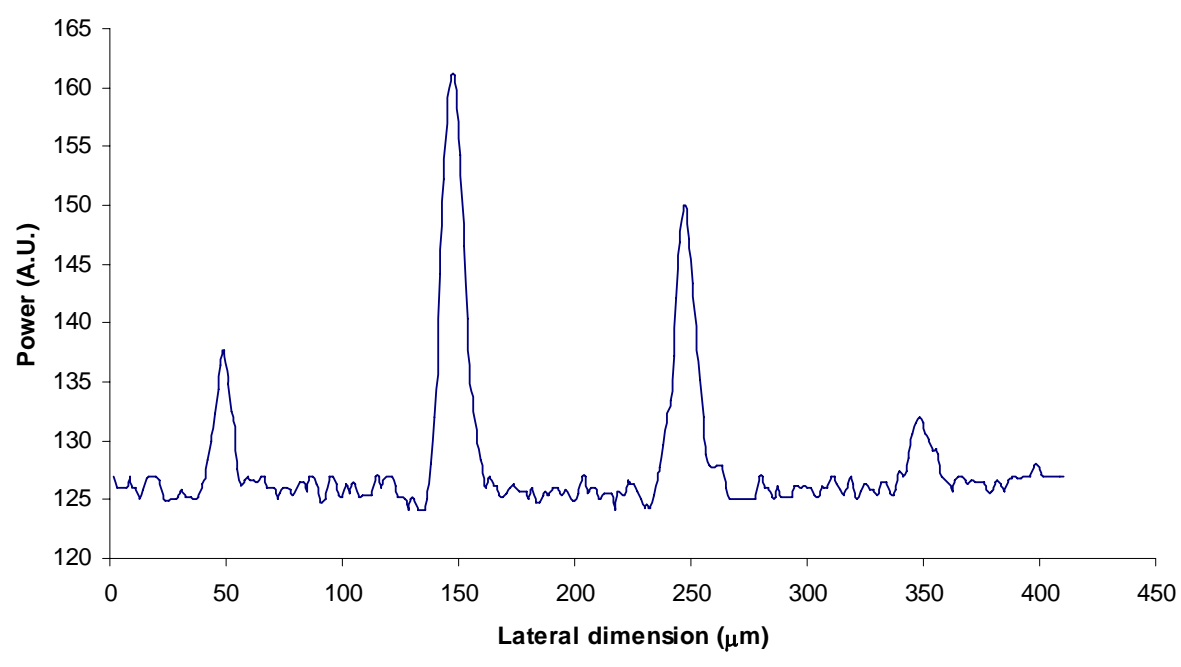

Figure 3.5. Output Power Distribution of an Array of Widely Spaced Waveguides

\subsection{LWIR Optical Fiber Research}

During FY 2006, work began on investigating the current state of mid-IR transmitting optical fibers. Different fibers were procured and discussions were initiated with several manufacturers to explore to the possibility of having singlemode mid-IR fibers custom fabricated. This work was leveraged by another NA-22 project (PL211c). A large core fusion splicer was procured to develop fiber tapers and fused core 
fiber couplers. The development of fiber components and singlemode fibers will have a strong impact on the development of a small from factor QCL transmitter.

\subsection{QC Laser Fiber Coupling Experiments}

The first fiber-coupled laser system, shown in Figure 3.6, used a large core $\mathrm{As}_{2} \mathrm{~S}_{2}$ fiber $(1000-\mu \mathrm{m}$ diameter) procured from Amorphous Materials Inc. The fiber is placed in the QC laser mount and precisely coupled using a 3 -axis positioner. The measured normalized transmission after a 1-m-long propagation is 0.57 where 1.0 would be without any loss. This leads to a coupling coefficient of $100 \%$, taking into account the two Fresnel reflections $\left(n_{0}=2.81\right)$, the propagation losses $(0.3 \mathrm{~dB} / \mathrm{m})$, and that all the output light is collected on the detector. The major contribution here is the two Fresnel reflections that account for $41 \%$ of the power reduction. Anti-reflection coatings on the fiber ends could significantly reduce these losses. The laser power measurement is also limited in its accuracy; hence, the coupling coefficient is realistically $95 \pm 5 \%$.
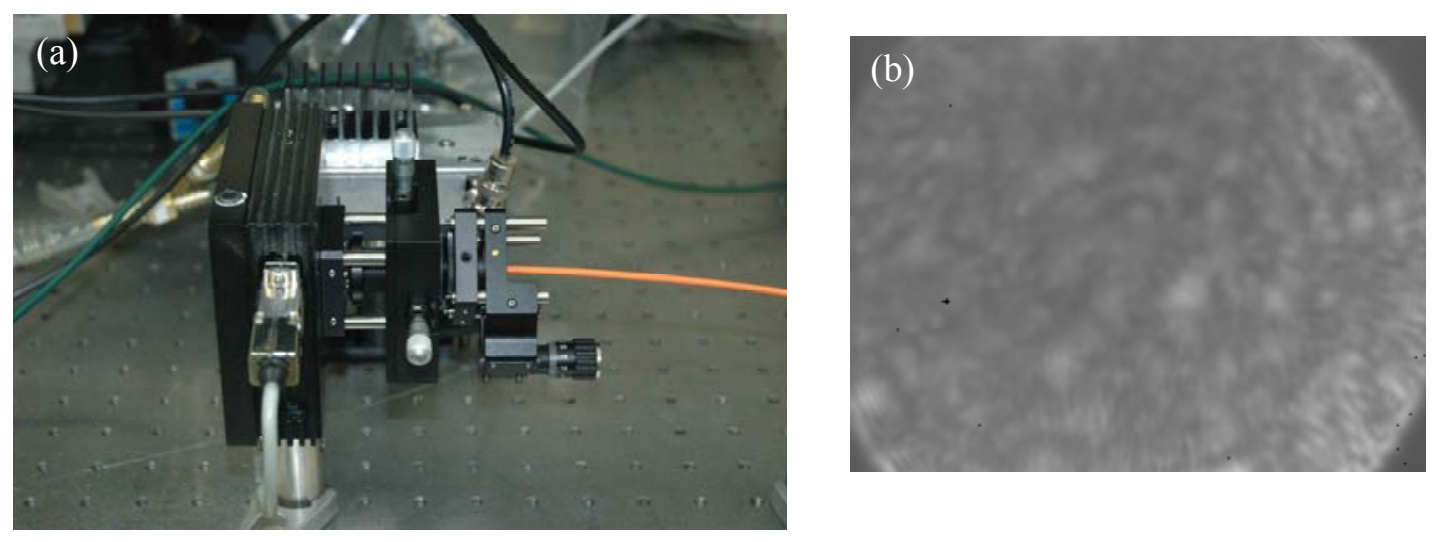

Figure 3.6. QCL Fiber-Coupling Experiments. (a) Fiber coupled laser mount. The fiber is in the orange tube. (b) Near field output of the fiber.

For other applications, however, a high brightness source is needed and therefore will require a singlemode output. Currently, there is no commercially available optical fiber that transmits in the midIR that is singlemode, although CorActive produces a commercially available $\mathrm{As}_{2} \mathrm{Se}_{3}$ fiber that supports four modes at $8.5 \mu \mathrm{m}$. Testing of this fiber showed that it had very good optical properties, including low numerical aperture, reasonable losses, and high quality modal output. It is possible to excite only the lowest order mode, as seen in Figure 3.7, but the mode profile is then very sensitive to the input conditions and any perturbation excites higher order modes.

The characterization of this fiber had the benefit of demonstrating that the manufacturer was able to produce high quality chalcogenide glass fiber, and we plan to have them produce custom singlemode fibers during FY 2007. This should be a straightforward process, requiring only a core diameter reduction in their existing fiber design. 


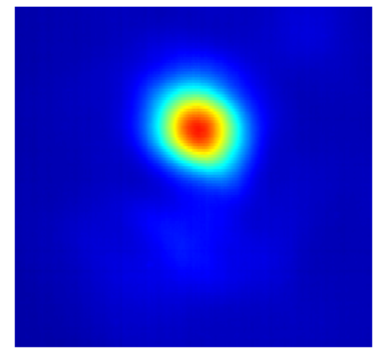

(a)

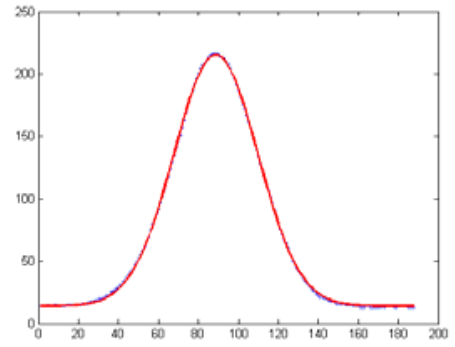

(b)

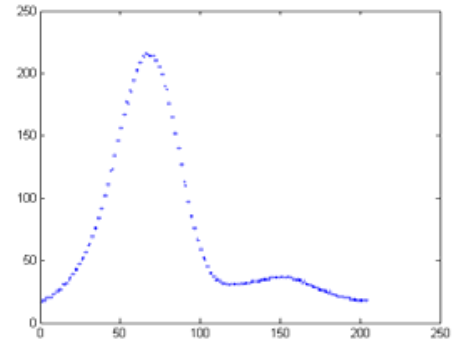

(c)

Figure 3.7. Mid-IR Fiber Output Mode Measurements. (a) Near field imaged on a camera, (b) horizontal profile, and (c) vertical profile. 


\subsection{Fabrication of Etched Chalcogenide Waveguides}

Photoinduced phenomenon in amorphous chalcogenide glasses, especially $\mathrm{As}_{2} \mathrm{~S}_{3}$ and $\mathrm{As}_{2} \mathrm{Se}_{3}$, has been extensively studied (Kobolov and Tanaka 2001). Exposure to sub band-gap laser illumination energies results in an increase of the material's refractive index (Anheier et al. 2004), a property that has been widely exploited to make waveguide devices in the near-infrared region. More recently, waveguiding in the mid-IR region using an $8.77 \mu \mathrm{m}$ quantum cascade laser was demonstrated (Hô et al. 2006b), details for which can be found in Section 3 of this report. However, the process of fabricating waveguides using photodarkening exhausts the available dynamic range for index modulation and mandates extremely large separations between waveguides to prevent evanescent coupling to and from each other.

To take advantage of the photoinduced phenomenon, it is possible to fabricate waveguides using conventional chemical etch techniques followed by photomodification of the waveguide with appropriate structures. For instance, recording Bragg gratings on a fabricated waveguide provides the possibility of making couplers and cavities in the mid- and long-wave infrared region.

\subsection{Simulation of Etched Waveguides}

To guide the development of etched chalcogenide glass planar waveguides, numerical simulations were done. The simulated structure consisted of a $\mathrm{Si} / \mathrm{SiO}_{2}$ substrate with an $\mathrm{As}_{2} \mathrm{~S}_{3}$ cladding layer and $\mathrm{As}_{2} \mathrm{Se}_{3}$ guiding layer with a ridge structure. The etch depth (or ridge height) was explored using a finitedifference mode solver to determine what depth was required and what was the effect of changing the depth on the mode. A typical structure is modeled as a $10-\mu \mathrm{m}$ thick $\mathrm{As}_{2} \mathrm{~S}_{3}(n=2,4)$ cladding, a 4- $\mu \mathrm{m}$ thick $\mathrm{As}_{2} \mathrm{~S}_{3}(n=2.7)$ core, and a 5- $\mu \mathrm{m}$ wide $\mathrm{As}_{2} \mathrm{~S}_{3}$ ridge of a given thickness. For a ridge thickness of $0.5 \mu \mathrm{m}$, the mode is very large, being almost $100 \mu \mathrm{m}$ wide, shown in Figure 4.1.
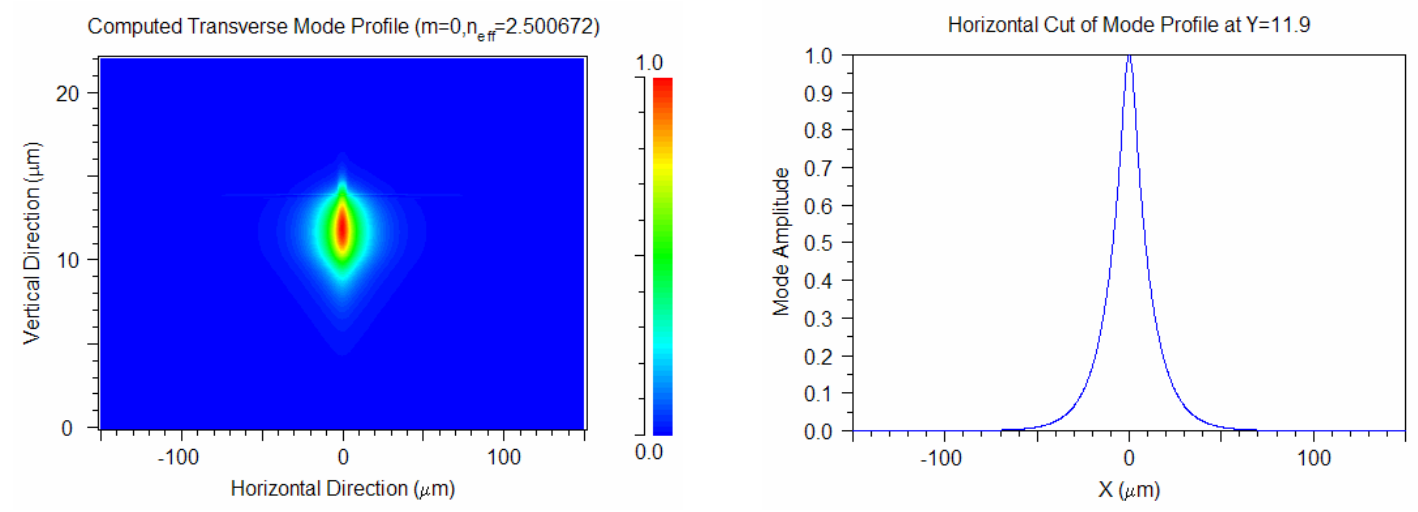

Figure 4.1. Simulated Mode Profiles for a Ridge Thickness of $0.5 \mu \mathrm{m}$

A thicker ridge confines the mode further, as can be seen with a $1.0 \mu \mathrm{m}$ ridge, leading to a $60 \mu \mathrm{m}$ wide mode, as shown in Figure 4.2. Therefore, ridges of $1.0 \mu \mathrm{m}$ or less can support a propagation mode, 
but exhibit very little lateral confinement. A ridge thickness of about $1.0 \mu \mathrm{m}$ is targeted, because smaller ridges do not offer much confinement and thicker ridges are difficult to achieve technically.
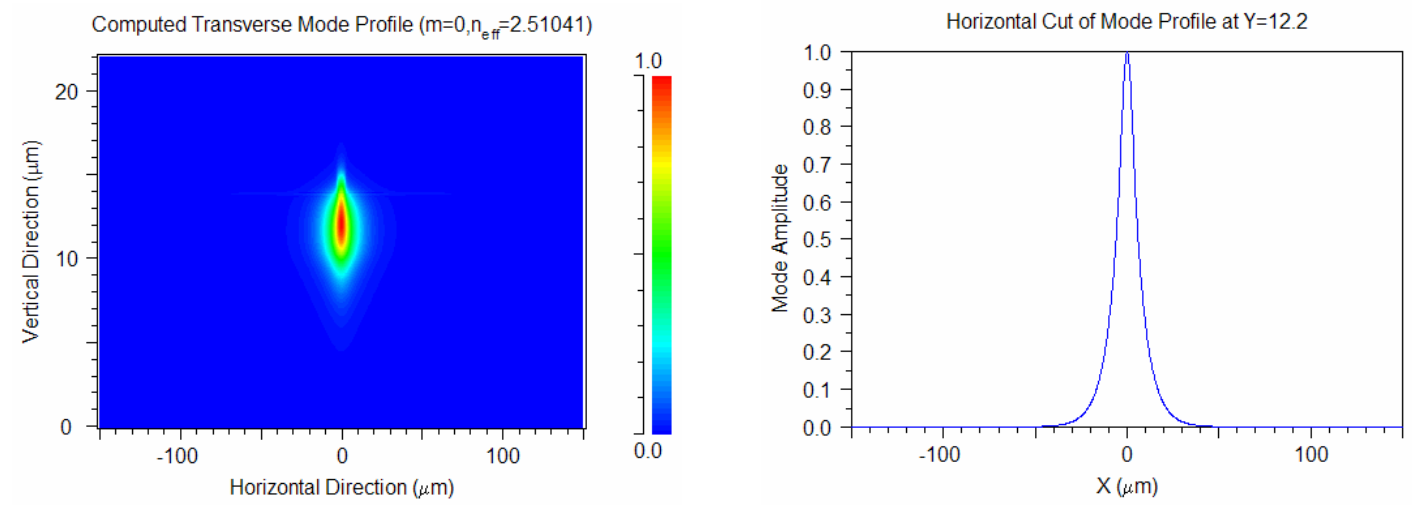

Figure 4.2. Simulated Mode Profiles for a Ridge Thickness of $1.0 \mu \mathrm{m}$

\subsection{Etching $\mathrm{As}_{2} \mathrm{Se}_{3}$ with Ethanolamine}

Based on simulations described in the previous section, a chemical etch process was developed to fabricate a ridge structures in $\mathrm{As}_{2} \mathrm{Se}_{3}$. A literature search showed that ethanolamine $\left(\mathrm{C}_{2} \mathrm{H}_{7} \mathrm{NO}\right)$, a basic solution, has been successfully used to etch $\mathrm{As}_{2} \mathrm{Se}_{3}$ with good surface quality (Ponnampalam et al. 2004; Bryce et al. 2004). Because the etch depth required for waveguides is on the order of $0.5-1 \mu \mathrm{m}$, it is critical to have precise control over the etch rate.

To measure etch rate of ethanolamine, $\mathrm{As}_{2} \mathrm{Se}_{3}$ films were deposited on $\mathrm{Si} / \mathrm{SiO}_{2}$ substrate using thermal deposition. A portion of the film was then removed from the substrate to reveal the $\mathrm{SiO}_{2}$ surface, thus forming a step. These samples were then dipped in ethanolamine at room temperature $\left(\sim 23^{\circ} \mathrm{C}\right)$ for durations ranging from 2-7.5 minutes with step height measurements obtained between every etch run. Figure 4.3 shows the measured step height after every etch run using a Zygo interferometer. The surface of the samples exhibited good surface quality after every etch step. 


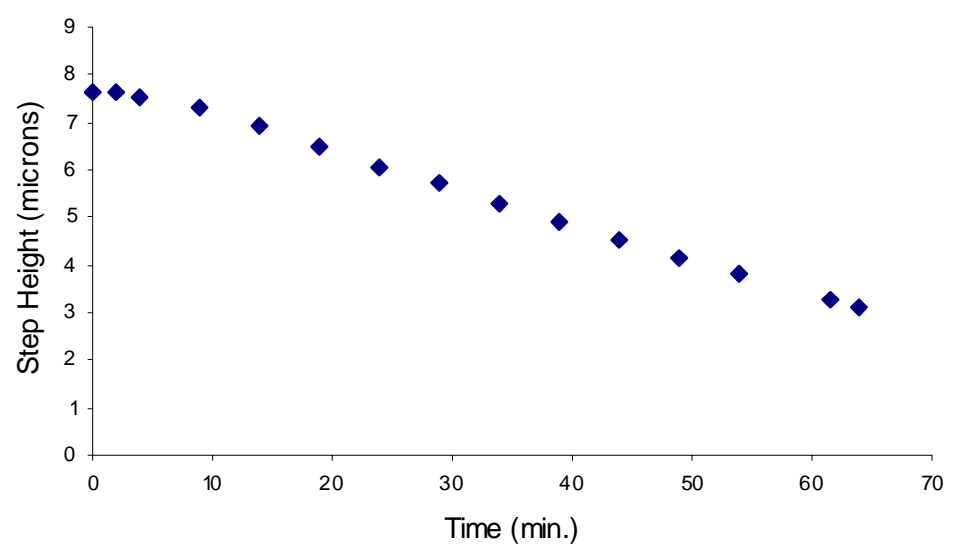

Figure 4.3. Step Heights of $\mathrm{As}_{2} \mathrm{Se}_{3}$ as a Function of Etch Time in Ethanolamine at $23^{\circ} \mathrm{C}$

Step height data showed that the etch rate in the first few minutes was slow, probably due to the presence of a surface layer. However, once this layer was removed the etch rate increased and exhibited a linear trend over a period of one hour. The data in Figure 4.4 shows the calculated etch rate (slope) of $\mathrm{As}_{2} \mathrm{Se}_{3}$ in ethanolamine after stripping away the surface layer. The calculated etch rate for this set of measurements was found to be $\sim 76 \mathrm{~nm} / \mathrm{min}$ at solution temperature of $23^{\circ} \mathrm{C}$. This value compares well with published data of $\sim 100 \mathrm{~nm} / \mathrm{min}$ at an elevated temperature of $52^{\circ} \mathrm{C}$ (Bryce et al. 2004). It must be noted that there was an uncertainty in step height measurement as it was not possible to make a measurement at the same location after every etch run.

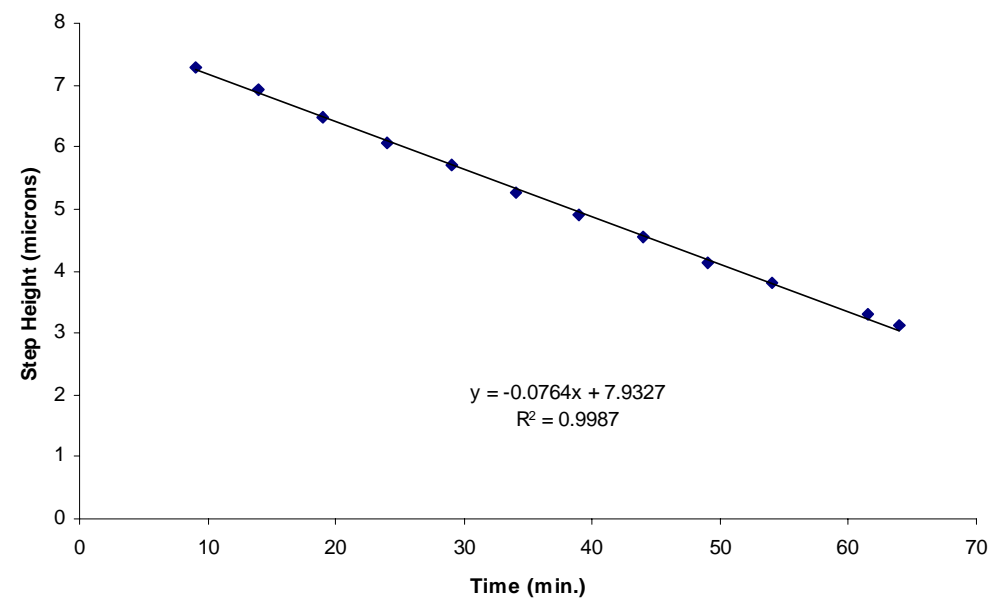

Figure 4.4. Step Heights of As $2 \mathrm{Se} 3$ as a Function of Etch Time in Ethanolamine at $23^{\circ} \mathrm{C}$ with Initial Data Points Removed to Correct for Surface Layer. The calculated etch rate was $\sim 76 \mathrm{~nm} / \mathrm{min}$. 


\subsection{Direct Writing and Patterning of Structures in $\mathrm{As}_{2} \mathrm{Se}_{3}$}

Exposure to UV essentially changes the refractive index of the exposed area and makes it slightly resistant to the etchant, in this case ethanolamine (Bryce et al. 2004). Due to a difference in the etch rates between the UV modified and unmodified regions, a step structure is etched into $\mathrm{As}_{2} \mathrm{Se}_{3}$ glass. The step height is purely a function of the difference in etch rates and the thickness of the exposed region (Krishnaswami et al. 2004). Once the exposed region has been etched away, the step height does not change anymore.

Samples of amorphous $\mathrm{As}_{2} \mathrm{Se}_{3}$ glass coated on $\mathrm{Si} / \mathrm{SiO}_{2}$ substrate were used for direct UV writing and patterning of structures to explore direct write in $\mathrm{As}_{2} \mathrm{Se}_{3}$. A mask with coarse grating lines was placed directly on the $\mathrm{As}_{2} \mathrm{Se}_{3}$ surface and exposed to $600 \mathrm{~W}\left(\sim 10 \mathrm{~mW} / \mathrm{cm}^{2}\right)$ of $\mathrm{UV}$ for $600 \mathrm{~s}$. Figure 4.5 shows the results from a Zygo optical profilometer of the $\mathrm{As}_{2} \mathrm{Se}_{3}$ surface after an accelerated ethanolamine etch for $2 \mathrm{~min}$ at a temperature of $45^{\circ} \mathrm{C}$. A step height of $100 \pm 5 \mathrm{~nm}$ was measured after nullifying the slope in the measurement. Here, the penetration depth of $U V$ in $\mathrm{As}_{2} \mathrm{Se}_{3}$ is very small, on the order of few $\mathrm{nm}$, resulting in a very thin surface modified layer. Consequently, there was no appreciable change in step height even after a second etch step of the same duration.

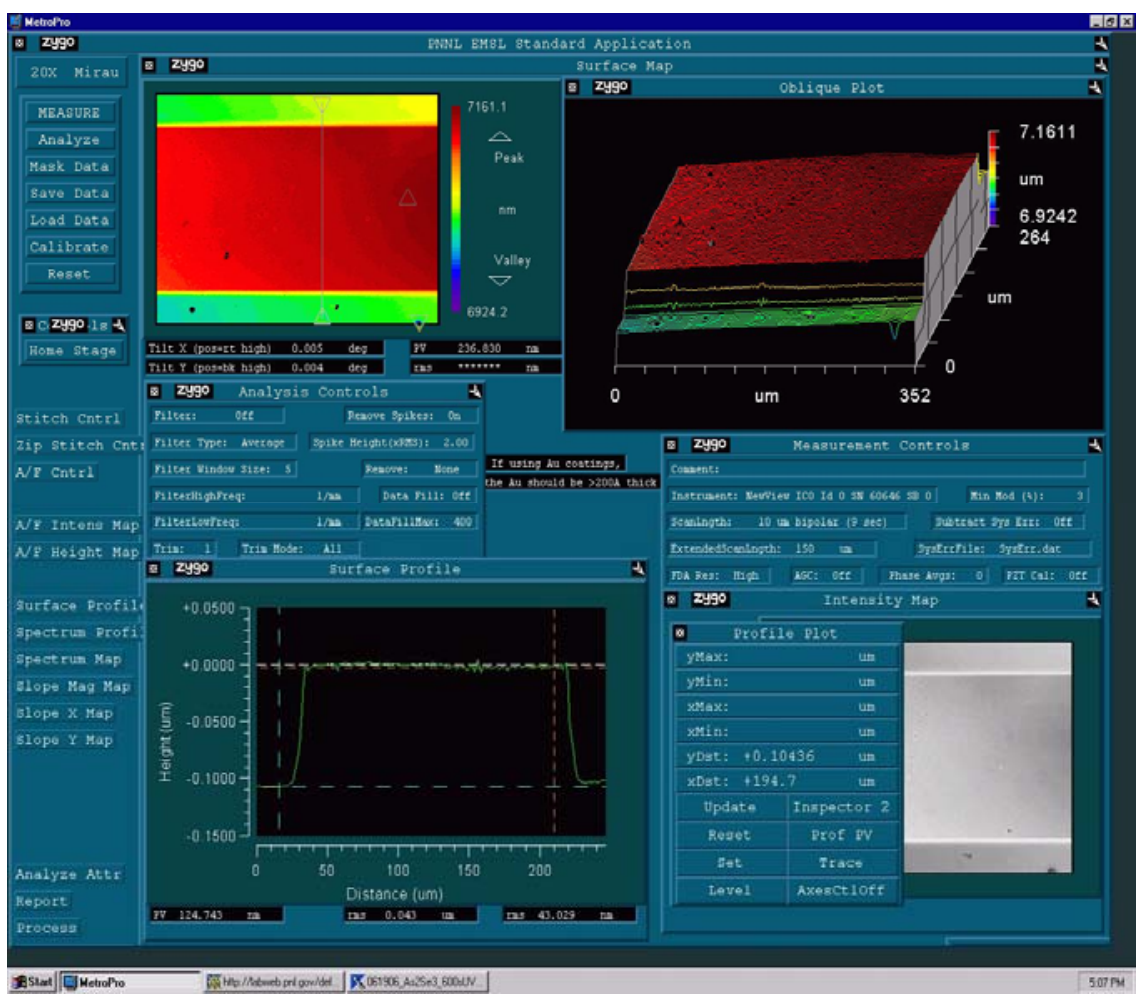

Figure 4.5. Step Height Measurements of a Direct Write Process Using Ultraviolet Flood Lamp and Ethanolamine Etch. The maximum step height obtained was $\sim 100 \pm 5 \mathrm{~nm}$. 
To increase the thickness of the modified region, the $514 \mathrm{~nm}$ laser line of an Argon laser was used to expose a mask for $20 \mathrm{~min}$ using a power density of $2.5 \mathrm{~mW} / \mathrm{cm}^{2}$. The penetration depth in $\mathrm{As}_{2} \mathrm{Se}_{3}$ at this wavelength is several hundred $\mathrm{nm}$ which when etched in ethanolamine for $2 \mathrm{~min}$ produced a step height of $\sim 685 \mathrm{~nm}$, as shown in Figure 4.6.

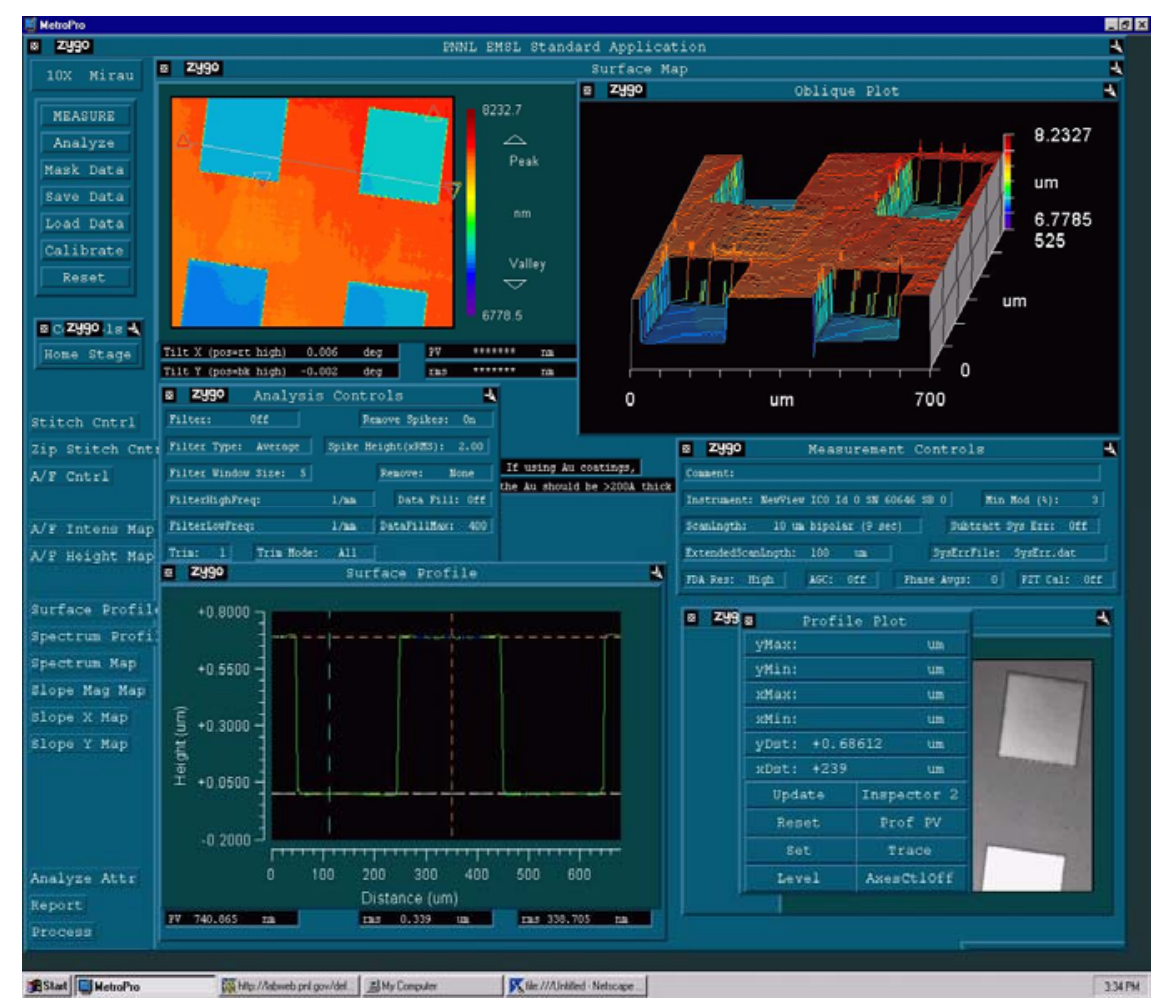

Figure 4.6. Step Height Measurements of a Direct Write Process Using an Argon Laser $(514 \mathrm{~nm})$ and Ethanolamine Etch. The maximum step height obtained was $\sim 685 \pm 5 \mathrm{~nm}$.

\subsection{Next Phase in $\mathrm{As}_{2} \mathrm{Se}_{3}$ Waveguide Fabrication}

Exposure to the $514 \mathrm{~nm}$ line of the Argon laser provides sufficient penetration depth to produce the necessary ridge heights for fabricating waveguides structures in $\mathrm{As}_{2} \mathrm{Se}_{3}$ glass. The next step towards the fabrication of waveguide structures in $\mathrm{As}_{2} \mathrm{Se}_{3}$ is the design and procurement of an appropriate mask and pattern transfer onto $\mathrm{As}_{2} \mathrm{Se}_{3}$. For this purpose a $100 \mathrm{~mm}$ mask with waveguide widths ranging from 2 to $20 \mu \mathrm{m}$ has been procured and fabrication runs are planned.

One of the major the challenges that lie ahead are the optimization of the aspect ratio using the direct write method. The direct write method, though easy and efficient in implementation, has its limitations and may not work for feature sizes smaller than $10 \mu \mathrm{m}$. It is necessary to explore other conventional photolithography in conjunction with wet and dry etch techniques to obtain small feature sizes. 


\subsection{QC Laser Optical Design}

QCLs have a large divergence in the fast axis (direction normal to the laser propagation axis) making efficient design of coupling and collimating optics paramount to the success of the photonics program. It will be shown in the Metrology section that far-field divergence numbers for QCL devices are typically $70^{\circ} \times 32^{\circ}$ for present devices. These divergence values equate to $1 / \mathrm{e}^{2}$ half angle divergence angles of $58.7^{\circ} \times 27.14^{\circ}$, respectively. This means that the fast axis sets the limit on optical throughput and the $1 / \mathrm{e}^{2}$ numerical aperture should be set at a minimum of at least $0.85\left(\operatorname{Sin}\left[58.7^{\circ}\right]\right)$. A typical QCL far-field divergence pattern showing this high divergence in shown in Figure 5.1.

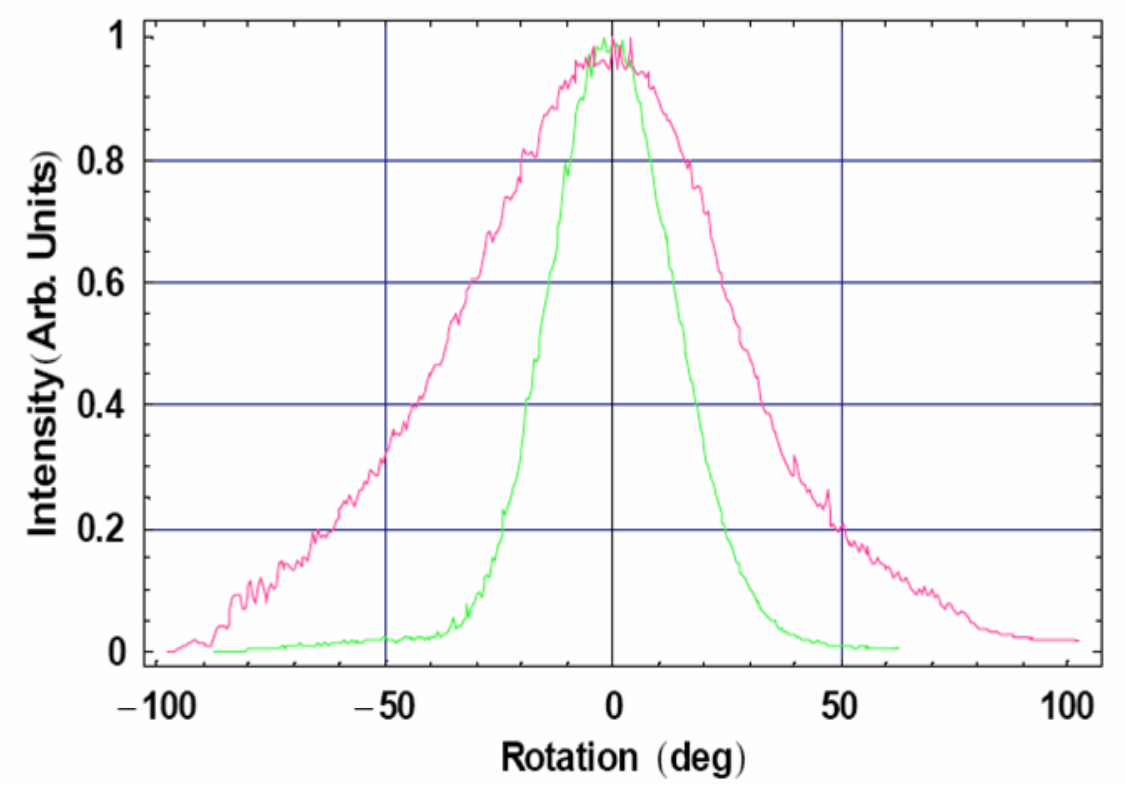

Figure 5.1. Divergence Plots Showing the Fast (red) and Slow (green) Axes Intensity Profiles for a Room Temperature QCL. The FWHM values are $70^{\circ} \times 32^{\circ}$.

\subsection{Collimation Lens Design - Variant 1}

The divergence data presented in the Figure 5.1 sets the minimum numerical aperture requirement necessary to efficiently collect light emitted from the laser to the $1 / \mathrm{e}^{2}$ power levels and was found to be 0.85 in the fast axis. The physical aperture of the lens was fixed at $6.35 \mathrm{~mm}$ to exploit standard commercial mounting hardware. Germanium was selected as the optical material because of its high index and ease of diamond turning. The optimum design that resulted is meniscus-shaped with a convex aspheric and concave spherical surface. The meniscus best-form shape is due to the high index of refraction of Germanium; and for high index material, a meniscus shape can be shown to provide the optimum shape for minimum spherical aberration (Welford 1986) for either the object or image at infinity. Of course, we also have recourse to an aspherical surface to further minimize spherical aberration, which was used on the first (convex) surface. The polynomial representation of the aspheric surface sag, $z(r)$, is determined by the following equation 


$$
Z=\frac{c r^{2}}{1+\sqrt{1-(1+k) c^{2} r^{2}}}+a_{2} r^{2}+a_{4} r^{4}+a_{6} r^{6}+a_{8} r^{8}+a_{10} r^{10}
$$

where $c=1 /$ radius of curvature, and $k$ is the conic constant. The concave spherical surface is described by the same equation for the case of $k$ equal to zero, as well as all of the aspheric terms equal to zero. The design is summarized in Table 5.1.

Table 5.1. Summary of Design Parameters for the 0.85 NA Collimating Lens

\begin{tabular}{||l|l||}
\hline Design Wavelength & $8.5 \mu \mathrm{m}$ \\
\hline Numerical Aperture & 0.85 \\
\hline Effective Focal Length & $1.9 \mathrm{~mm}$ \\
\hline Back Focal Length (Working Distance) & $1.3 \mathrm{~mm}$ \\
\hline Clear Aperture & $4.8 \mathrm{~mm}$ \\
\hline Outer Diameter & $6.35 \mathrm{~mm}$ \\
\hline Central Thickness & $2.0 \mathrm{~mm}$ \\
\hline Lens Material & Germanium \\
\hline
\end{tabular}

A summary of the finished design is shown in Figure 5.2. This figure presents the 2D layout along with plots of RMS wave front error (WFE) vs. field height, longitudinal aberration, and modulation transfer function (MTF). The design is diffraction-limited up to field heights of $\pm 10 \mu \mathrm{m}$. Practically speaking, since this lens is intended for laser collimation, this means that there can be a relative displacement between the object (laser facet) and lens axis by $\pm 10 \mu \mathrm{m}$ and the aberrations induced by this misalignment (primarily coma) that degrade the output collimated beam would still meet diffraction limit criteria of RMS WFE $<\lambda / 14$. The ability to mount and manipulate the lens to a precision of $\pm 10 \mu \mathrm{m}$ is very achievable using commercial opto-mechanical components.

The design shown in Figure 5.2 was fabricated using single-point diamond turning and found to be much better than diffraction limited with a Strehl ratio of 0.9 or better for all lenses. The diffraction limit expressed in terms of Strehl ratio is 0.8 , so it can be appreciated that the lenses far exceeded design expectations.

\subsection{Collimation Lens Design - Variant 2}

Although the first design met all design goals, its clear aperture of $4.8 \mathrm{~mm}$ can result in noticeable divergence if the beam is allowed to propagate more than several hundred millimeters as can be seen in Eq. (5.2) that describes beam waist size as a function of propagation distance. 


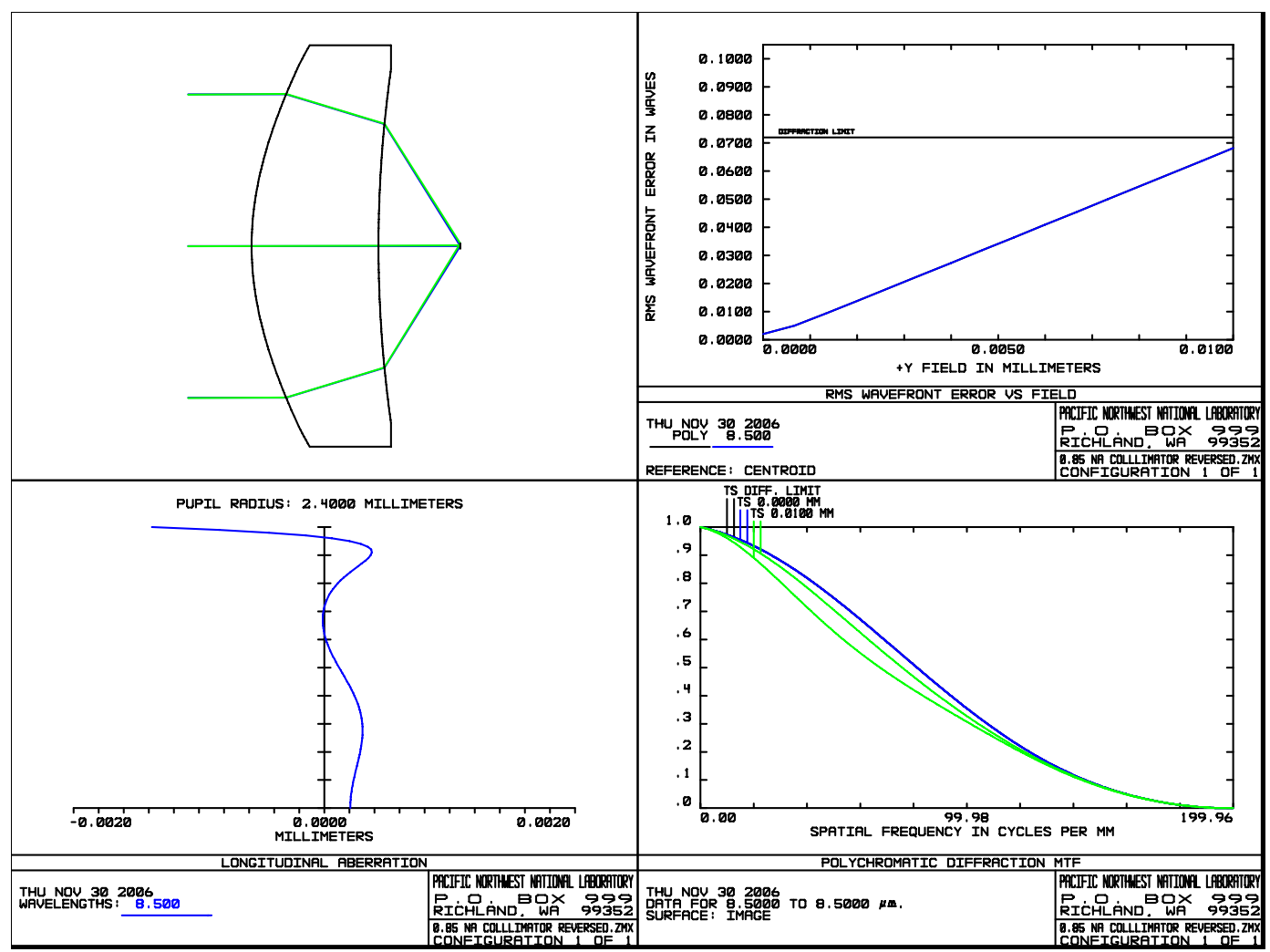

Figure 5.2. The 0.85 NA Lens System Summary Showing the 2D Optical Layout, RMS vs. WFE Plot, Longitudinal Aberration Plot and Modulation Transfer Function. The predicted (and actual performance) far exceeds the theoretical diffraction limit.

$$
\omega(z)^{2}=\omega_{0}^{2}\left(1+\left(\frac{\lambda z}{\pi \omega_{0}^{2}}\right)^{2}\right)
$$

So, for example, at a wavelength of $8.5 \mu \mathrm{m}$, a beam having a waist radius of $2.4 \mathrm{~mm}$ will diverge and increase in size by $10 \%$ after it propagates only $447 \mathrm{~mm}$, and have a Rayleigh range of $2.2 \mathrm{~m}$ (distance over which the beam expands by less than $\sqrt{ } 2$ times the initial waist size. So, if we want to propagate a beam with minimum expansion, it is best to start with the largest beam size possible. Additionally, since we need to mate the collimated beam output to many "nominal" size catalog lenses, a larger beam diameter is a better match to $12.7 \mathrm{~mm}$ diameter lenses that are often used in the laboratory and readily available from optics vendors. The design of Variant 2 is summarized in Table 5.2.

Essentially, the lens was scaled up in size from the Variant 1 design and re-optimized. A summary graphic showing the design performance is shown in the Figure 5.3. Theoretical performance was predicted to be slightly worse than the Variant 1 lens, but not dramatically so. All things equal, aberrations scale with size and it is easier to make a high-performance small lens than a larger lens having the same NA. 
Table 5.2. Lens Parameter Summary for the Second Collimating Lens Variant

\begin{tabular}{||l|l||}
\hline Design Wavelength & $8.5 \mu \mathrm{m}$ \\
\hline Numerical Aperture & 0.85 \\
\hline Effective Focal Length & $3.03 \mathrm{~mm}$ \\
\hline Back Focal Length (Working Distance) & $2.05 \mathrm{MM}$ \\
\hline Clear Aperture & $7.5 \mathrm{~mm}$ \\
\hline Outer Diameter & $10.0 \mathrm{~mm}$ \\
\hline Central Thickness & $3.0 \mathrm{~mm}$ \\
\hline Lens Material & Germanium \\
\hline \hline
\end{tabular}

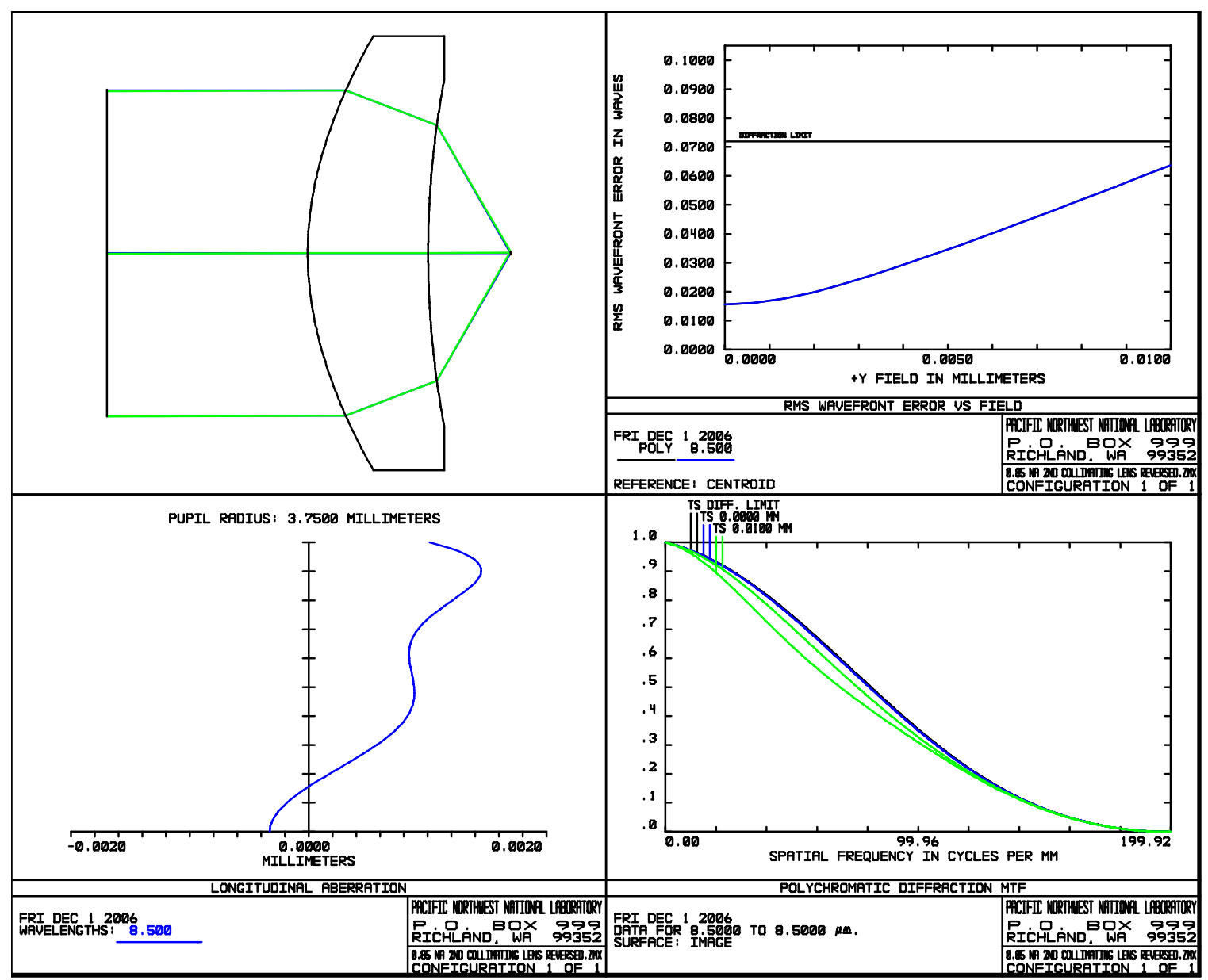

Figure 5.3. Variant 2 Germanium Collimating Lens Summary. Performance is still predicted to exceed diffraction-limited performance although the larger lens has slightly poorer performance as seen in the longitudinal aberration plot (lower left quadrant). However, field and MTF performance are roughly equivalent to the smaller Variant 1 design. 
The Variant 2 lens was fabricated using single-point diamond turning and demonstrated diffractionlimited performance but fell somewhat short of the Variant 1 lens performance. Based on the distribution of the spherical aberration values found for the lens batch, this was probably due to the lens blanks being cut on the thicker side of the nominal $3.0 \mathrm{~mm}$ dimension, although they were still within the tolerance specified to the vendor. All of the third order spherical aberration coefficients measured were positive, rather than randomly distributed positive and negative values. A consistently positive value for spherical aberration could indicate an incorrect figure or transcription error in entering the lens prescription into the tool path generator of the diamond turning machine. Both positive and negative values indicate a variation in thickness clustered about the nominal value of central thickness. However, the sag table generated by the fabrication software was checked against the design sag table and no errors were found, leading to the conclusion of a too-thick lens. In future designs, the central thickness tolerance will be tightened up to $\pm 25 \mu \mathrm{m}$ from the existing $\pm 50 \mu \mathrm{m}$ limit.

\subsection{Mid-IR Optical Fiber and Waveguide Coupling Lenses}

Due to the choice of cladding materials available for waveguide fabrication using chalcogenide glass, as well as the variety of numerical apertures characteristic of chalcogenide-based mid-IR fibers, a toolbox of fiber and waveguide couple lenses was designed to span a reasonable spectrum of anticipated device parameters. Because commercially available IR micro lenses exist and are adequate for low numerical aperture ( 0.1 NA or less) applications, designs for Germanium aspheric lenses with numerical apertures of $0.3,0.6$, and 0.8 were undertaken. Physical aperture sizes of $12.7 \mathrm{~mm}$ were selected in order to use commercial mounts. The designs were consciously restricted to plano-convex shapes (although this is not the best-form shape at higher numerical apertures) in order to maximize the working distance of the lens and simplify mounting. A summary of the resulting designs is shown in Table 5.3. Summary graphics of the three lenses are shown in Figures 5.4, 5.5, and 5.6.

Table 5.3. Summary of the Design Parameters for the Three Plano-Convex Germanium Lenses Design for General Purpose Waveguide and Fiber Research

\begin{tabular}{||l|l|l|l||}
\hline & \multicolumn{1}{|c|}{ 0.3 NA Lens } & \multicolumn{1}{|c|}{ 0.6 NA Lens } & \multicolumn{1}{|c||}{ 0.8 NA Lens } \\
\hline Design Wavelength & $10.0 \mu \mathrm{m}$ & $10.0 \mu \mathrm{m}$ & $10.0 \mu \mathrm{m}$ \\
\hline Effective Focal Length & $18.6 \mathrm{~mm}$ & $8.0 \mathrm{~mm}$ & $5.0 \mathrm{~mm}$ \\
\hline Back Focal Length & $17.4 \mathrm{~mm}$ & $6.75 \mathrm{~mm}$ & $3.75 \mathrm{~mm}$ \\
\hline Clear Aperture & $11.43 \mathrm{~mm}$ & $11.43 \mathrm{~mm}$ & $11.43 \mathrm{~mm}$ \\
\hline Physical Aperture & $12.7 \mathrm{~mm}$ & $12.7 \mathrm{~mm}$ & $12.7 \mathrm{~mm}$ \\
\hline Central Thickness & $5.0 \mathrm{~mm}$ & $5.0 \mathrm{~mm}$ & $5.0 \mathrm{~mm}$ \\
\hline Lens Material & Germanium & Germanium & Germanium \\
\hline \hline
\end{tabular}




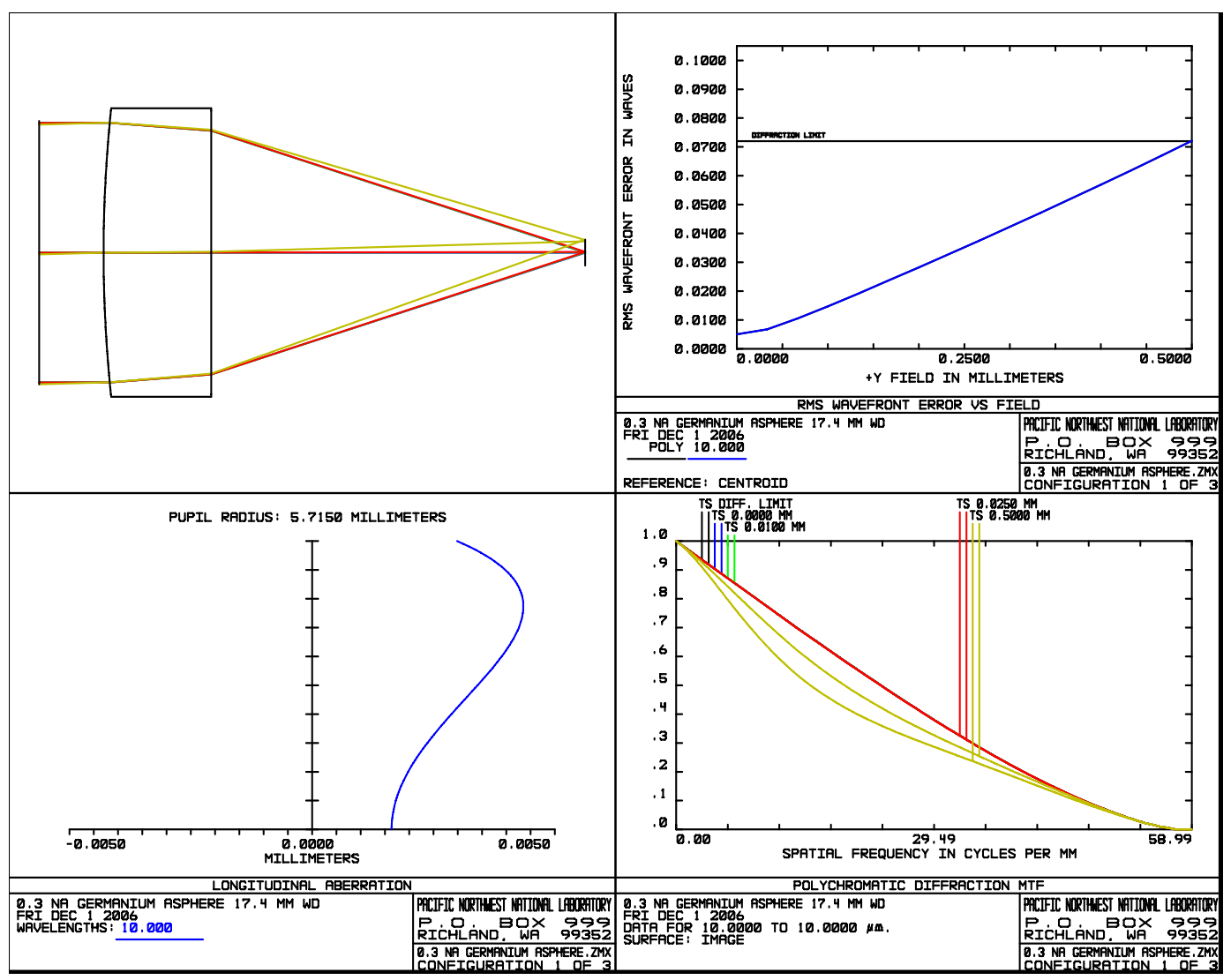

Figure 5.4. System Summary Graphic for the 0.3 NA Lens Showing Diffraction-Limited Performance for Field Heights (lens displacements) up to $\pm 500 \mu \mathrm{m}$

Of note is the extremely good field performance of the 0.3 NA lens which allows a centering error of up to $\pm 0.5 \mathrm{~mm}$ and still delivers diffraction-limited performance, as well as the excellent field performance of the $0.6 \mathrm{NA}$ lens with a centering tolerance of $\pm 50 \mu \mathrm{m}$ before the lens ceases to be diffraction-limited. The $0.8 \mathrm{NA}$ is well corrected for having one surface constrained to be flat or plano which removes one degree of freedom, and the lens performance is good enough to serve double duty as a QCL collimating lens for experiments in which efficiency of light collimated from the QCL is not paramount, such as waveguide characterization studies. No commercial mid-IR lenses exist having the performance of these three custom Germanium aspheres, especially with physical diameters of $12.7 \mathrm{~mm}$, which made their design and fabrication crucial to the success of the IR photonics research program. All three lenses were fabricated using single-point diamond turning and found to far exceed the theoretical diffraction limit. Test data will be presented in the metrology section of this report to justify this statement. 


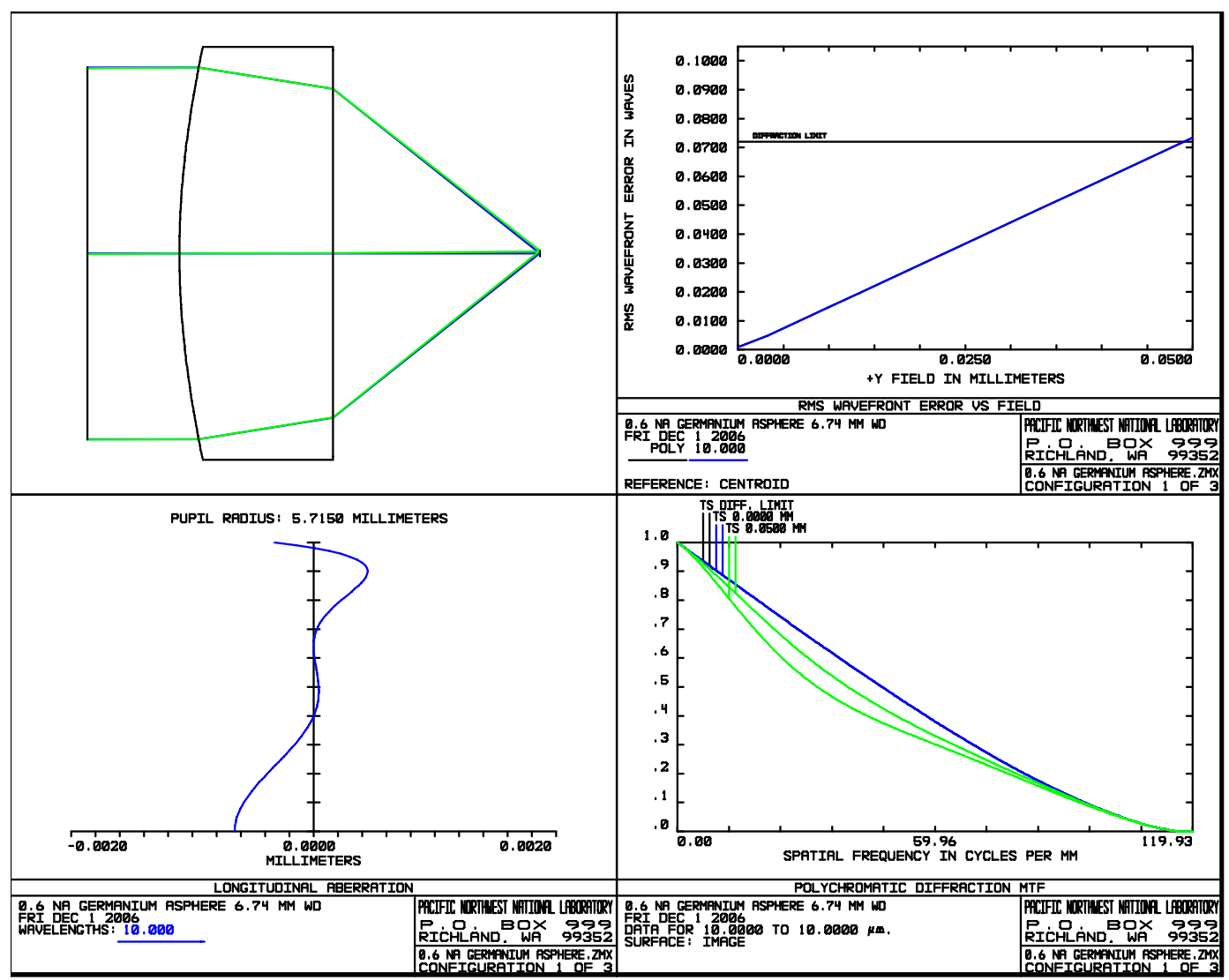

Figure 5.5. System Summary Graphic for the 0.6 NA Germanium Coupling Lens. Note the very good axial performance visible in the longitudinal aberration plot (lower left quadrant) and RMS WFE versus field plot (upper right quadrant). The lens remains diffraction limited for field heights up to $\pm 50 \mu \mathrm{m}$. 


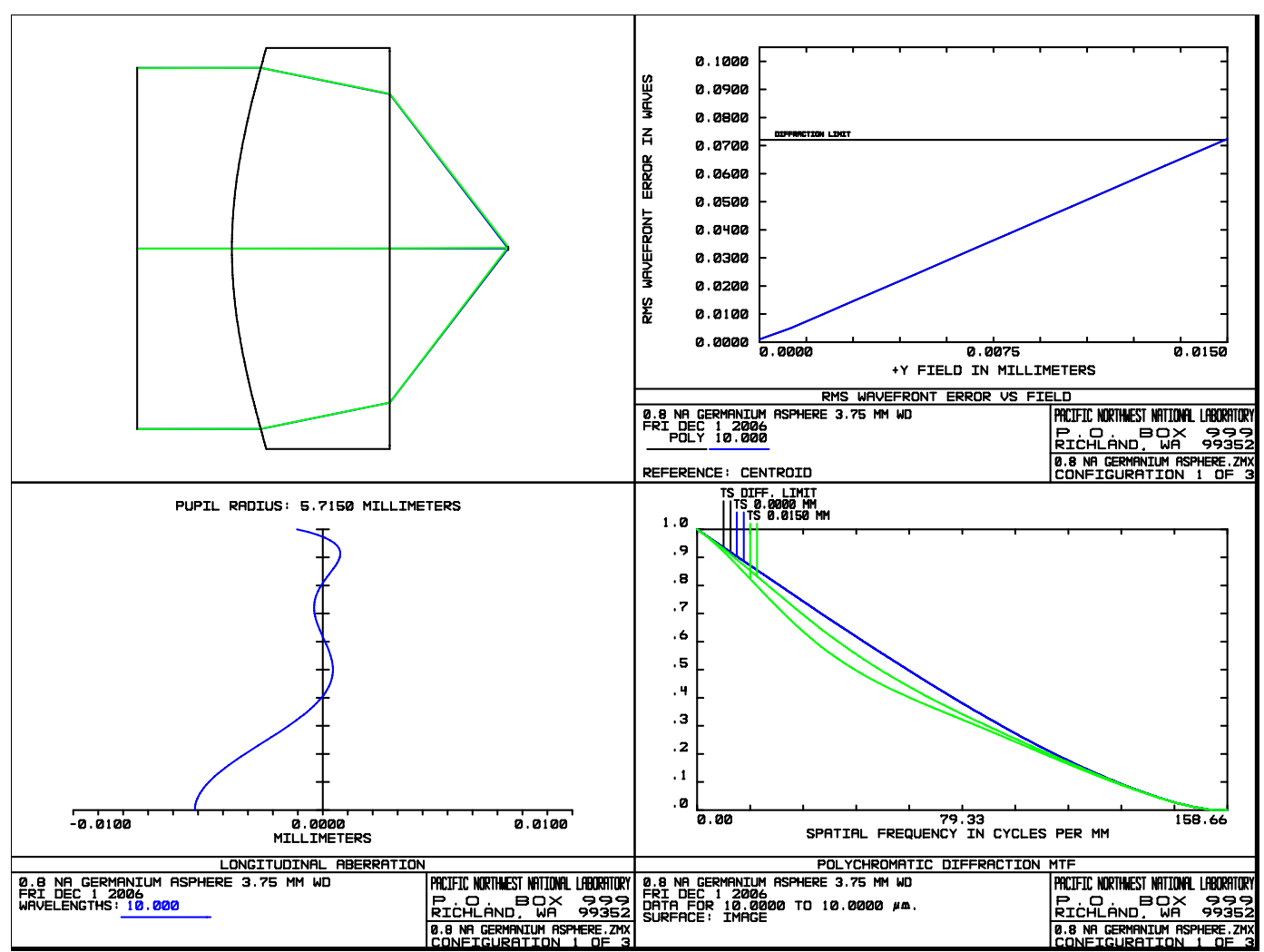

Figure 5.6. A System Summary Graphic of the 0.8 NA Plano Convex Germanium Lens Designed for Photonics Research. Note the excellent field performance (up to $\pm 15 \mu \mathrm{m}$ of lens decentration is tolerated) shown in the upper right quadrant and extremely good longitudinal aberration performance (lower left quadrant).

\subsection{Summary}

Motivation, design parameters, and summary ideal performance were presented for five unique IR lens designs that were fabricated to facilitate the progress of research in the IR photonics program. These included two 0.85 NA Germanium QCL collimating lenses, and three Germanium utility lenses having numerical apertures of $0.3,0.6$, and 0.8 , respectively. The lack of availability of commercial sources for these lenses highlights the shortfall of enabling technology necessary to work with QCL devices and associated active and passive IR devices. Although we have the tools and resources to design and procure these specialty lenses, the design, procurement, and fabrication lead times necessary to obtain these lenses slows research progress and must be kept in mind when planning research efforts. 


\subsection{Advanced LWIR Optical Metrology}

The QCL technology has provided a high-brightness, room temperature source ideally suited to remote sensing applications. The successful utilization of the QCL is dependent on developing highperformance optical components. In addition, chalcogenide optical fibers and waveguide devices require specialized optics not readily available from catalog sources. Therefore, custom high- to moderatenumerical aperture aspheric optics were designed and fabricated for use in our development activities. This section outlines PNNL's development efforts to characterize the QCL emission beam properties and the optical performance of the custom LWIR optics.

\subsection{QCL Beam Divergence Characterization}

The efficient design of collection optics for QCLs require a priori knowledge of its divergence angles in both slow and fast axes. For this, an apparatus to measure the raw divergence of QCLs was assembled. The measured QCLs were based on double phonon resonance design with emission wavelengths of $8.77 \mu \mathrm{m}$ at room temperature (Hofstetter et al. 2001; Liu et al. 2006t). The QCLs, fabricated by Maxion Technologies, comprised 35 periods of InGaAs/AlInAs grown by molecular beam epitaxy on an InP substrate, capped with an InP clad layer. The ridges were first dry-etched to form cavities that were $\sim 2.1 \mu \mathrm{m}$ high, $\sim 15 \mu \mathrm{m}$ wide and $3 \mathrm{~mm}$ long. Next, a dielectric layer was deposited followed by the formation of an $\mathrm{Au}$ contact layer. The QCLs were mounted epi-up on modified C-mounts with indium solder.

The divergence apparatus comprised a rotary stage, with a step resolution of $0.5^{\circ}$, with the test QCL facet at the center of rotation. The lasers were operated above their threshold current of $\sim 1 \mathrm{~A}$ at a frequency of $32 \mathrm{kHz}$ and a pulse width of $1 \mu \mathrm{s}$. A liquid nitrogen cooled $\mathrm{HgCdTe}$ detector with a $1-\mathrm{mm}^{2}$ area was used to measure emitted power at a distance of about $150 \mathrm{~mm}$. The emission profiles typically showed a divergence of $62^{\circ} \times 32^{\circ} \mathrm{FWHM} \pm 2^{\circ}$ for the fast and slow axes, respectively, as shown in Figure 6.1, with fringe structures superimposed on the fast axis profiles. Additionally, the fast axis profiles also showed significant power levels out to $\pm 70^{\circ}$ angles as shown below.

The presence of fringing and its magnitude can be directly correlated to the setback of the QCL, ranging 1 to $20 \mu \mathrm{m}$, die from the edge of the C-mount. Due to the wide fast axis angular divergence, even a minimal setback results in reflections from the lip and clipping from the edge of the C-mount, as illustrated in Figure 6.2, resulting in a superposition of interference and diffraction effects in the far-field. For fast axis profiles measured, $-90^{\circ}$ and $+90^{\circ}$ correspond to the bottom and top of the lasers, respectively.

This was confirmed by simulating the beam propagation from a setback QCL using an implicit finitedifference method, the result of which was used to calculate far-field distribution. However, fringing can be suppressed by properly placing the die flush with the edge of the C-mount. For instance, the divergence profile of a QCL with minimal $(\sim 1 \mu \mathrm{m})$ die setback from the edge, shown in Figure 6.3, exhibited a much lower fringing magnitude. These measurements highlight the need for careful QCL mounting on the sub-mounts to minimize far-field structure in the beam. 


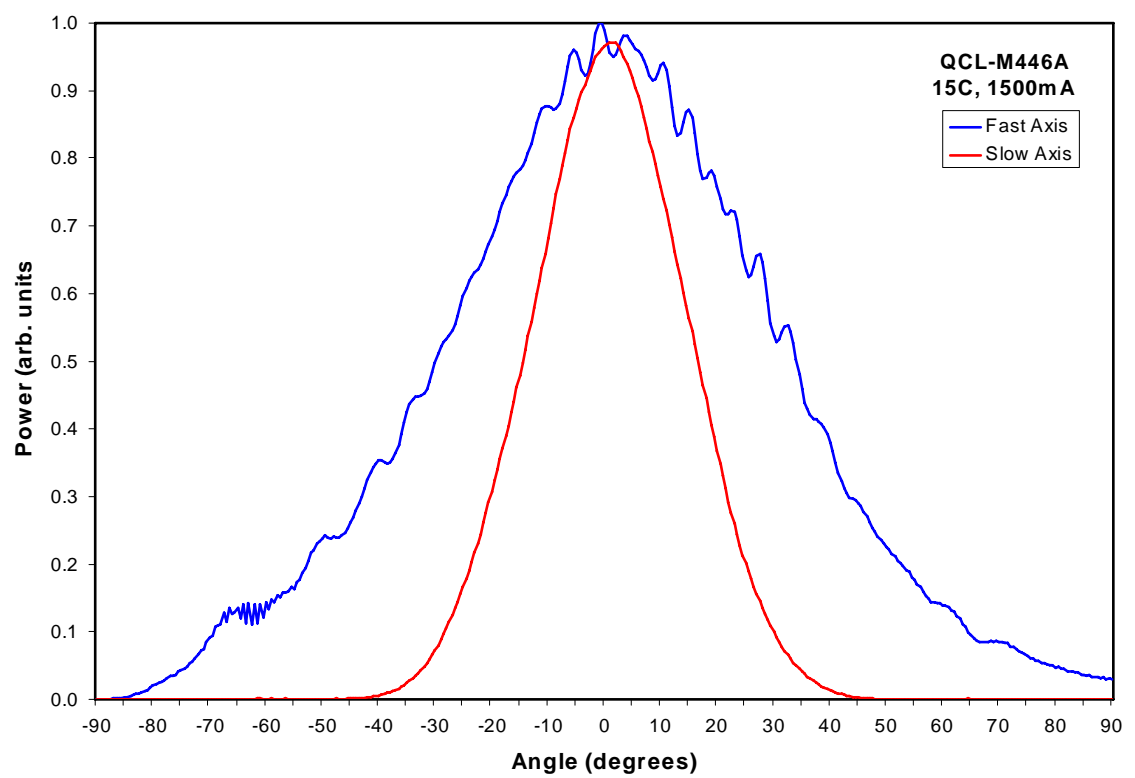

Figure 6.1. Typical Emission Profile of a QCL along the Fast and Slow Axes with the Presence of Fringing Superposed on the Fast Axis. The set back of the laser die form the edge of the C-Mount was measured to be $\sim 8 \mu \mathrm{m}$.

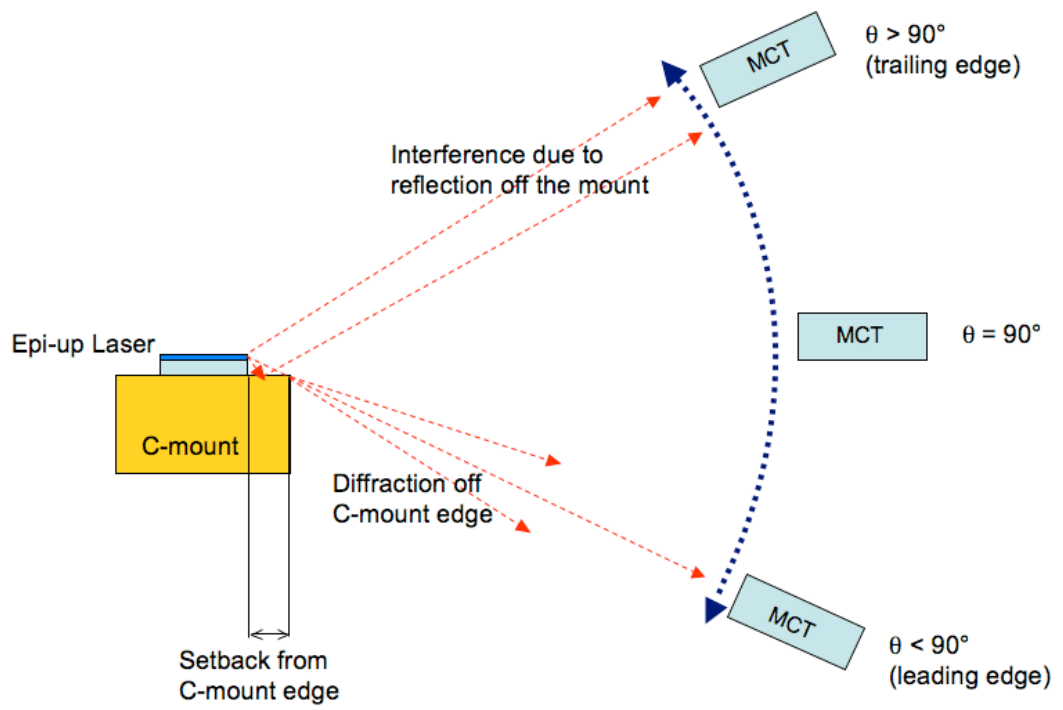

Figure 6.2. Fast Axis Fringing Occurs When a QCL Die is Set Back from the Edge of the C-Mount Causing Reflections from the Lip and Clipping from the Edge 


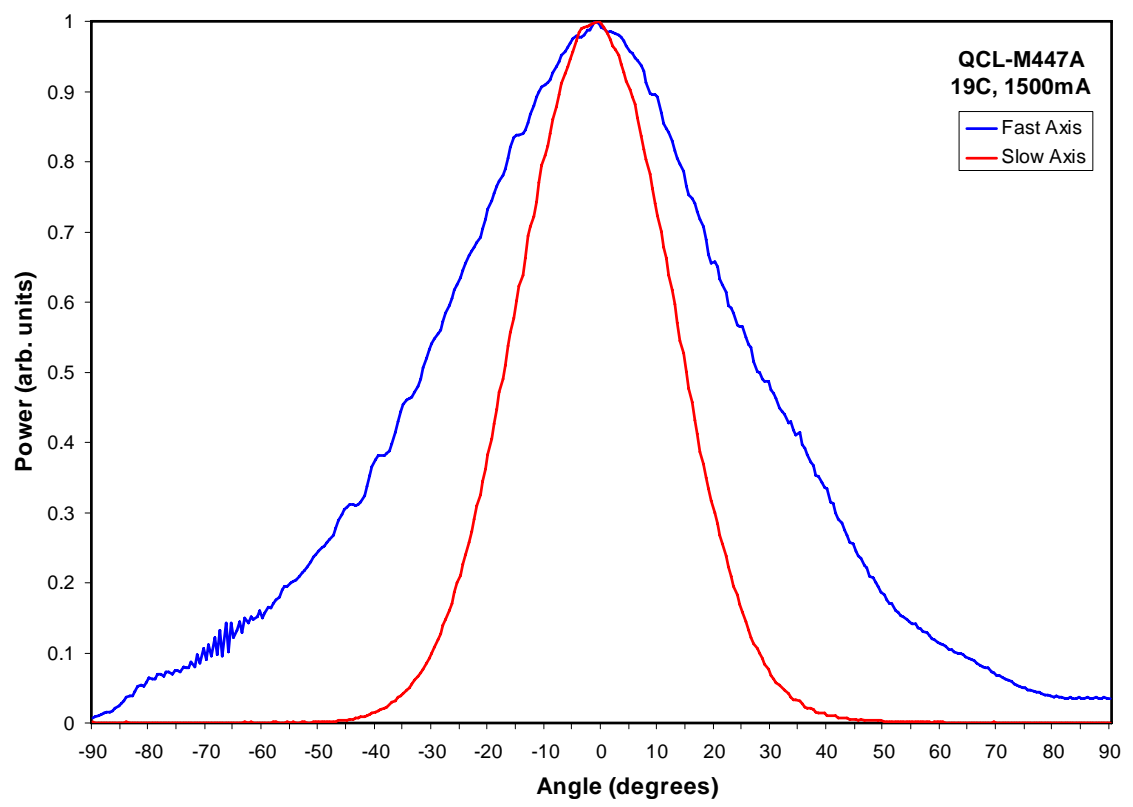

Figure 6.3. Typical Emission Profile of a QCL along the Fast and Slow Axes with Reduced Fast Axis Fringing. The laser die set back from the edge of the C-mount was measured to be $\sim 1 \mu \mathrm{m}$.

\subsection{Germanium Asphere Lens Characterization}

Far-field divergence measurement results, especially with respect to the fast axis, are essential to the design of efficient collimation optics. The focusing optics design is application-specific and their requirements vary from one application to another. In this case, custom lenses were designed and fabricated for the collimation and focusing of QCLs, specifically for characterizing the optical performance of chalcogenide photonic devices and mid-IR fiber optics.

The collimating lens design was based on divergence measurements with a requirement to capture maximum emission, while the design of the focusing lens was based on a requirement of tightly focusing the collimated QCL beam into both optical fibers and chalcogenide waveguide structures. The aspheric lenses were designed using germanium (see Section 5 for more details) and fabricated using single-point diamond turning. The performance of these lenses was characterized using a LWIR Twyman-Green interferometer built during FY 2005 (Anheier et al. 2005) to quantify spherical aberrations and Strehl ratios of the individual lenses.

The LWIR interferometer presented here uses a tunable $\mathrm{CO}_{2}$ laser as its source emission with lines in the range of 9.3 to $10.8 \mu \mathrm{m}$. The 2.4-mm beam was expanded using a 10X telescope to produce a $\sim 25$-mm wide beam to completely fill the clear aperture of the lens under test. Figure 6.4 shows a schematic of the LWIR interferometer. The interferograms were recorded using an uncooled ferroelectric camera (Electrophysics, PV-320) with a $320 \times 240$ focal plane array of $50 \mu \mathrm{m} \times 50 \mu \mathrm{m}$ pixel dimensions. The interferometer was aligned to provide $\sim 10$ fringes on the sensor array. 


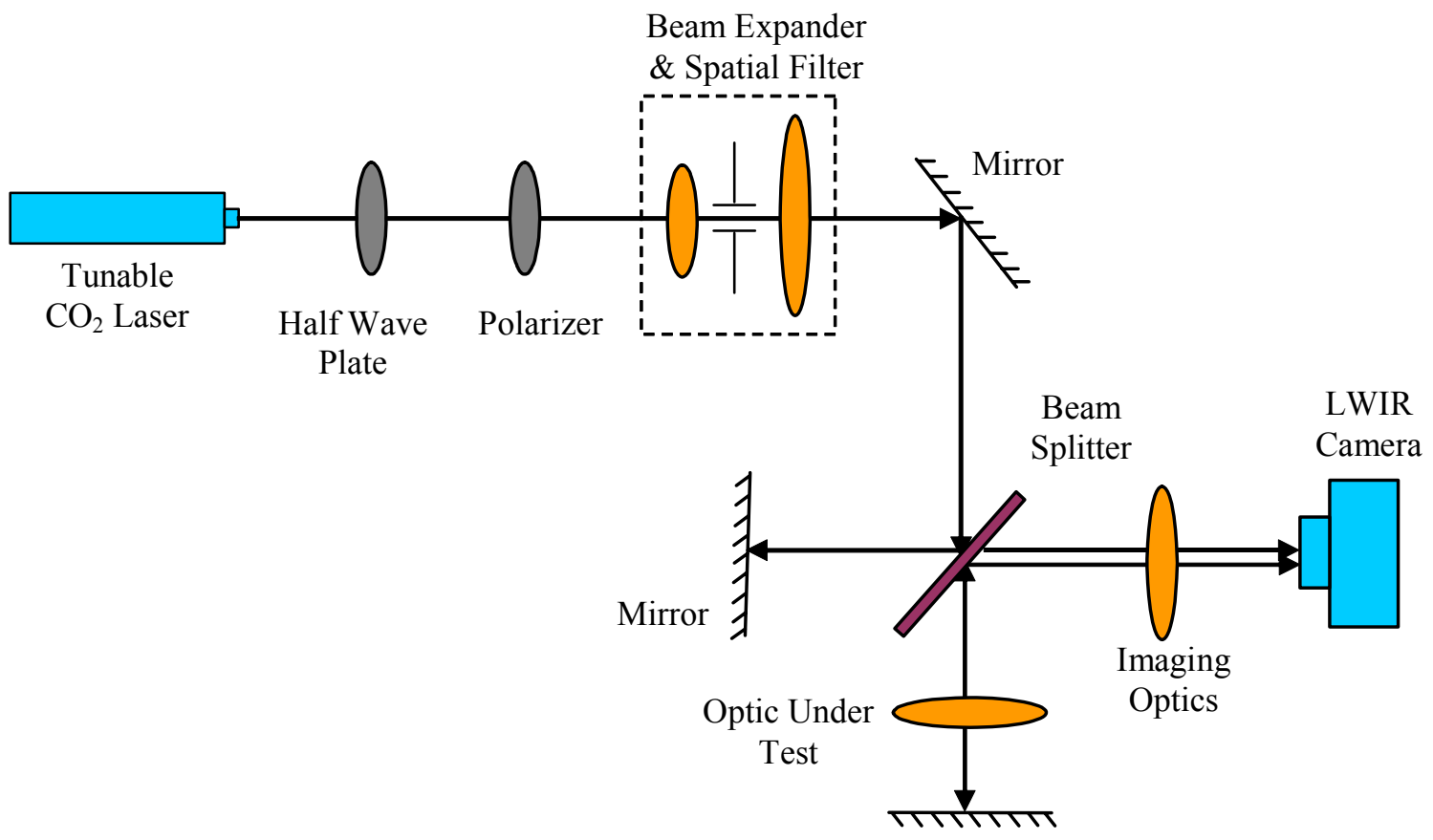

Mirror

Figure 6.4. Schematic of a LWIR Twyman-Green Interferometer to Measure Wavefront Aberrations in Custom Aspheres

Quick Fringe, a commercially available fringe analysis program, was used to analyze the interferograms obtained on the Twyman-Green interferometer. Figure 6.5 shows a screen capture of the fringe analysis for a 0.85 NA collimating lens with an outer diameter of $6.35 \mathrm{~mm}$ and a focal length of $1.88 \mathrm{~mm}$, measured at $9.4 \mu \mathrm{m}$. The observed Strehl ratio for this lens was 0.94 with spherical aberrations of 0.20 waves. Lenses that exhibit Strehl ratios $>0.8$ are considered to be diffraction-limited.

Germanium aspheres with a focal length of $25 \mathrm{~mm}$ and clear aperture of $10 \mathrm{~mm}$ were characterized. Figure 6.6 shows a screen capture of the fringe analysis for a typical 25-mm focal length asphere used for focusing the collimated QCL beam to a minimum spot size. Once again, it can be seen that the observed Strehl ratio for these focusing lenses is $>0.98$, implying that they exhibit diffraction-limited performance.

An analysis of all the focusing lenses showed that spherical aberrations ranged between \pm 0.5 waves. Figure 6.7 shows the statistical distribution of spherical aberrations for this lens set. It must be noted that Quick Fringe reports raw Zernike polynomials in a double-pass configuration. These polynomials need to be appropriately scaled to provide the Siedel coefficients. For the spherical term, the Siedel coefficient is $6 \times \mathrm{Z} 8$ for a single pass configuration and, hence, for the Twyman-Green configuration, the Siedel equivalent for the Zernike polynomial would be $3 \times \mathrm{Z} 8$. 


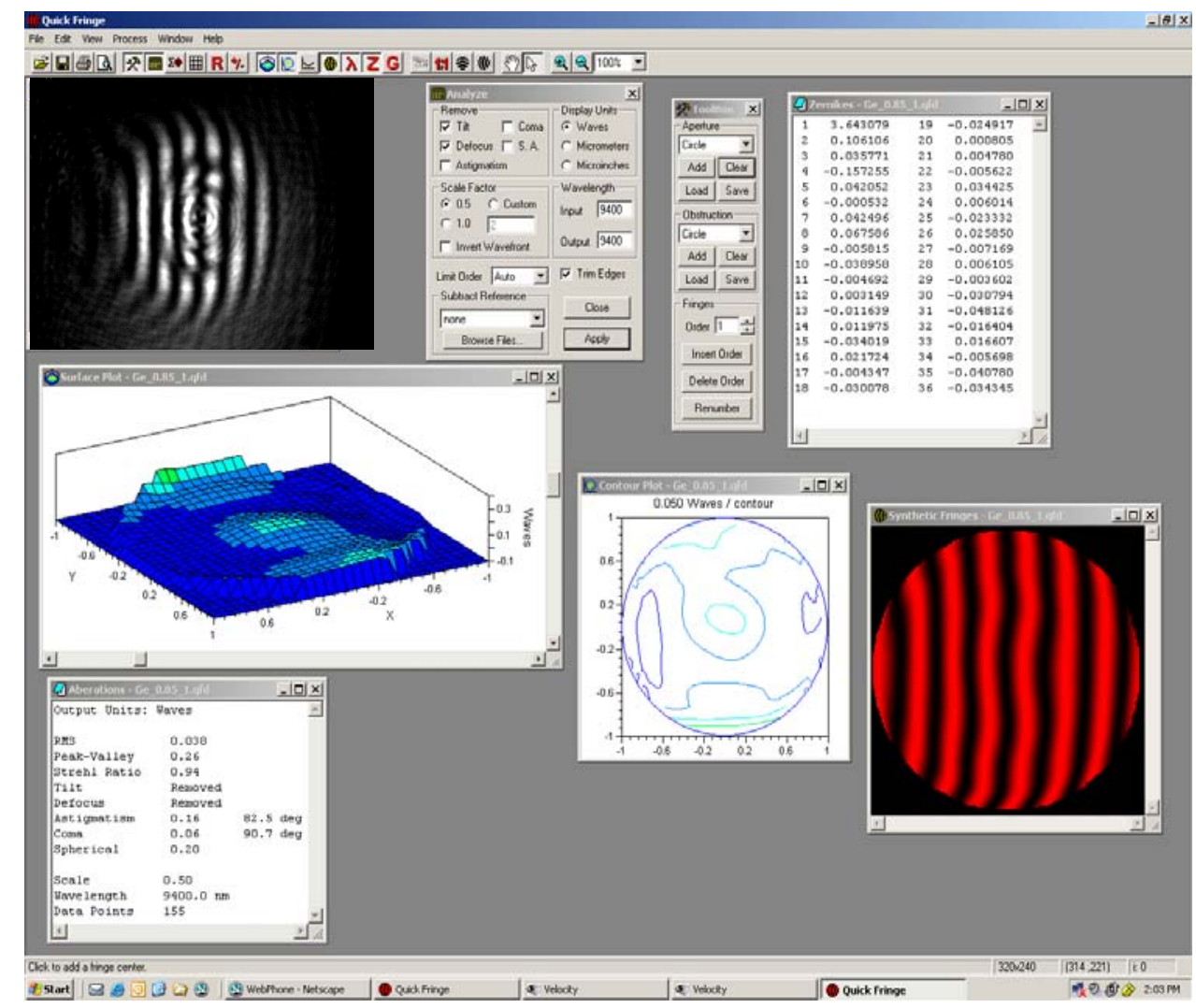

Figure 6.5. Screen Capture of the Fringe Analysis for a 0.85NA Ge Asphere Designed to Collimate QCLs 


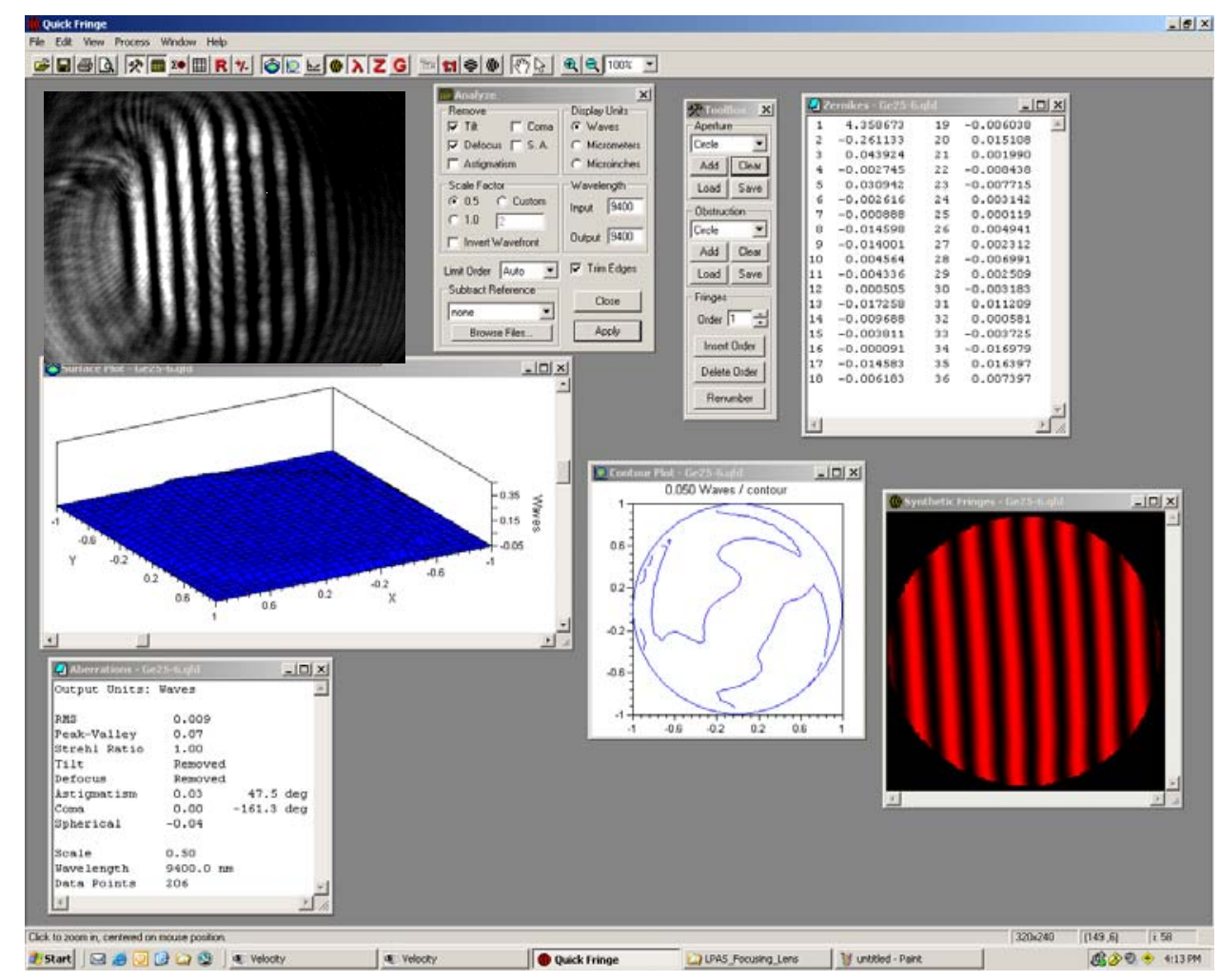

Figure 6.6. Screen Capture of the Fringe Analysis for a 25-mm Focal Length Ge Asphere Designed for Focusing the QCL Beam

Distribution of Spherical Aberrations in $12 \mathrm{~mm}$ Ge Lenses with EFL $25 \mathrm{~mm}$

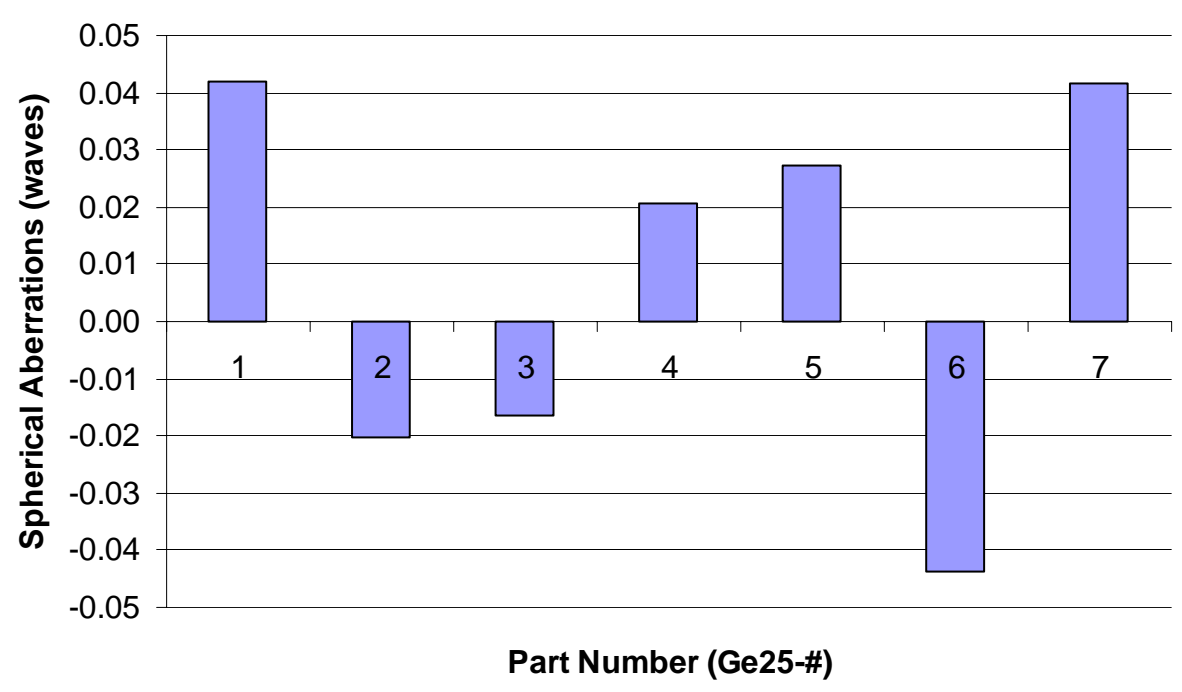

Figure 6.7. Statistical Distribution of Spherical Aberration Measured in $25 \mathrm{~mm}$ Focal Length Germanium Aspheres Designed for Focusing the QCL Beam 
Based on the performance results of the collimating and focusing lenses discussed earlier, a second set of collimating and focusing lenses were designed and fabricated. The collimating lens had a numerical aperture of 0.85 with an effective focal length of $3.0 \mathrm{~mm}$ and outer diameter of $10 \mathrm{~mm}$, while the focusing lens had effective focal length of $20 \mathrm{~mm}$ with an outer diameter of $12.7 \mathrm{~mm}$. Table 6.1 summarizes the performance data of the first and second set of collimating and focusing lenses. Spherical aberrations for the second version of focusing lenses ranged between 0.5 and 0.8 waves, implying that the central thickness was slightly larger than specified.

Table 6.1. Performance Characteristics for Custom-Made Collimating and Focusing Lenses for Waveguide Coupling and Chemical Sensing Applications

\begin{tabular}{||l|c|l|c|c|c||}
\hline \multicolumn{1}{|c|}{ Lens Type } & $\begin{array}{c}\text { Numerical } \\
\text { Aperture }\end{array}$ & EFL & $\begin{array}{c}\text { Strehl } \\
\text { Ratio }\end{array}$ & Spherical Aberrations & $\begin{array}{c}\text { Number of } \\
\text { Lenses }\end{array}$ \\
\hline Collimating (v1) & 0.85 & $1.88 \mathrm{~mm}$ & $>0.94$ & 0.20 waves & 1 \\
\hline Focusing (v2) & 0.20 & $25 \mathrm{~mm}$ & $>0.98$ & \pm 0.5 waves & 7 \\
\hline Collimating (v2) & 0.85 & $3.0 \mathrm{~mm}$ & $>0.82$ & $0.6 \pm 0.2$ waves & 13 \\
\hline Focusing (v2) & 0.25 & $20 \mathrm{~mm}$ & $>0.98$ & \pm 0.15 waves & 12 \\
\hline
\end{tabular}

Three sets of custom lenses were designed and fabricated for coupling to waveguides. These lenses had a numerical aperture of $0.3,0.6$, and 0.8 with an effective focal length of 18.0, 8.0, and $5.0 \mathrm{~mm}$, respectively. A summary of their characteristics is provided in Table 6.2. All waveguide coupling lenses exhibited diffraction-limited performance. Spherical aberrations for the $0.3 \mathrm{NA}$ lenses ranged between -0.05 and -0.10 waves. This implied that the central thickness of the lenses were slightly less than the specifications.

Table 6.2. Performance Characteristics for Custom-Made Waveguide-Coupling Lenses

\begin{tabular}{||c|c|c|c|c||}
\hline No. & $\begin{array}{c}\text { Numerical } \\
\text { Aperture }\end{array}$ & $\begin{array}{c}\text { Strehl } \\
\text { Ratio }\end{array}$ & Spherical Aberrations & $\begin{array}{c}\text { Number of } \\
\text { Lenses }\end{array}$ \\
\hline 1 & 0.3 & $>0.97$ & $-0.05 \pm 0.05$ waves & 3 \\
\hline 2 & 0.6 & $>0.96$ & \pm 0.7 waves & 4 \\
\hline 3 & 0.8 & $>0.88$ & \pm 0.16 waves & 10 \\
\hline
\end{tabular}

\subsection{Spot Size Measurements}

A confocal system using the first-generation 0.85 NA collimating lens and the 25-mm focusing lens, described in the previous section, was assembled and characterized with a QCL specifically for waveguide-coupling applications. The essentially aberration-free $25-\mathrm{mm}$ lens was used as a focusing lens in the spot size measurement. This lens system had a transverse magnification of $\sim 13$ and a longitudinal magnification of $\sim 175$. The operating parameters for the QCL were identical to those used in the divergence measurements. Spot size data for fast and slow axes were acquired at several locations within 
the focal region by scanning an $\mathrm{HgCdZnTe}$ detector (PD-10.6, Vigo Systems) with a $10 \mu \mathrm{m}$ wide slit in steps of $2 \mu \mathrm{m}$.

The second moment method (Siegman 1998) using a 1\% clip level was used to calculate spot radii and $M^{2}$. Figure 6.8 shows the measured spot sizes at various locations within the focal region yielding $M^{2}$ values of 1.22 and 1.81 for the slow and fast axes, respectively. Spot radii at focus, shown in Figures 6.9(a) and (b), were calculated to be 71.5 and $58.8 \mu \mathrm{m}$ for the slow and fast axes, respectively. The focal separation of $\sim 700 \mu \mathrm{m}$ between the slow and fast axis foci was due to intrinsic source astigmatism, measured to be $\sim 4 \mu \mathrm{m}$ which is less than half a wave. Astigmatism in diode lasers is caused by spatial variations in gain and index across the waveguide (Mansuripur and Wright 2002).

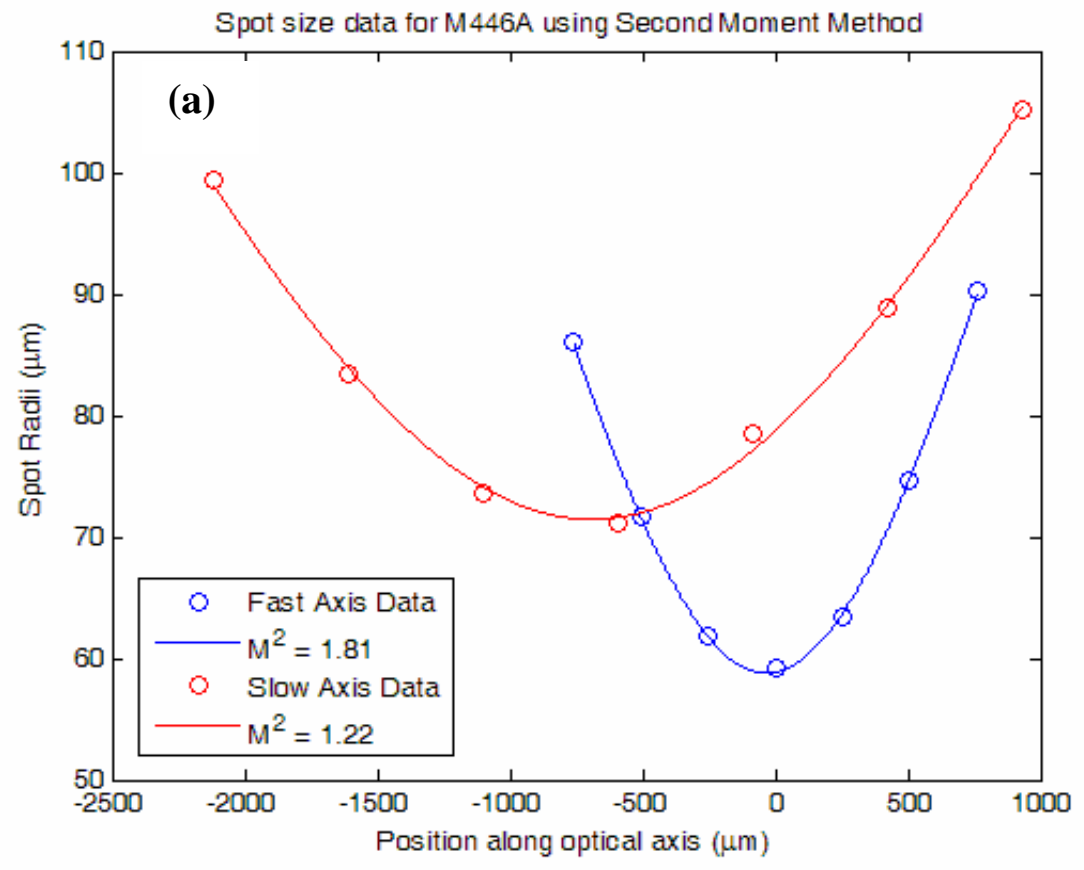

Figure 6.8. Spot Size Data Measured at Various Locations within the Focal Region. The $M^{2}$ fit was calculated using second moment method with a $1 \%$ clip.

The fast axis $M^{2}$ measurement was clearly influenced by the fast axis truncation at the $1 / \mathrm{e}^{2}$ diameter by the collimation optic. Uncorrected laser astigmatism and residual spherical aberration from the system optics have negligible contributions to the fast axis $M^{2}$ value (Siegman 1993). Even though $M^{2}$ measurements show reasonable performance for sensing applications, the small amount of laser astigmatism may require correction for high-performance applications. 

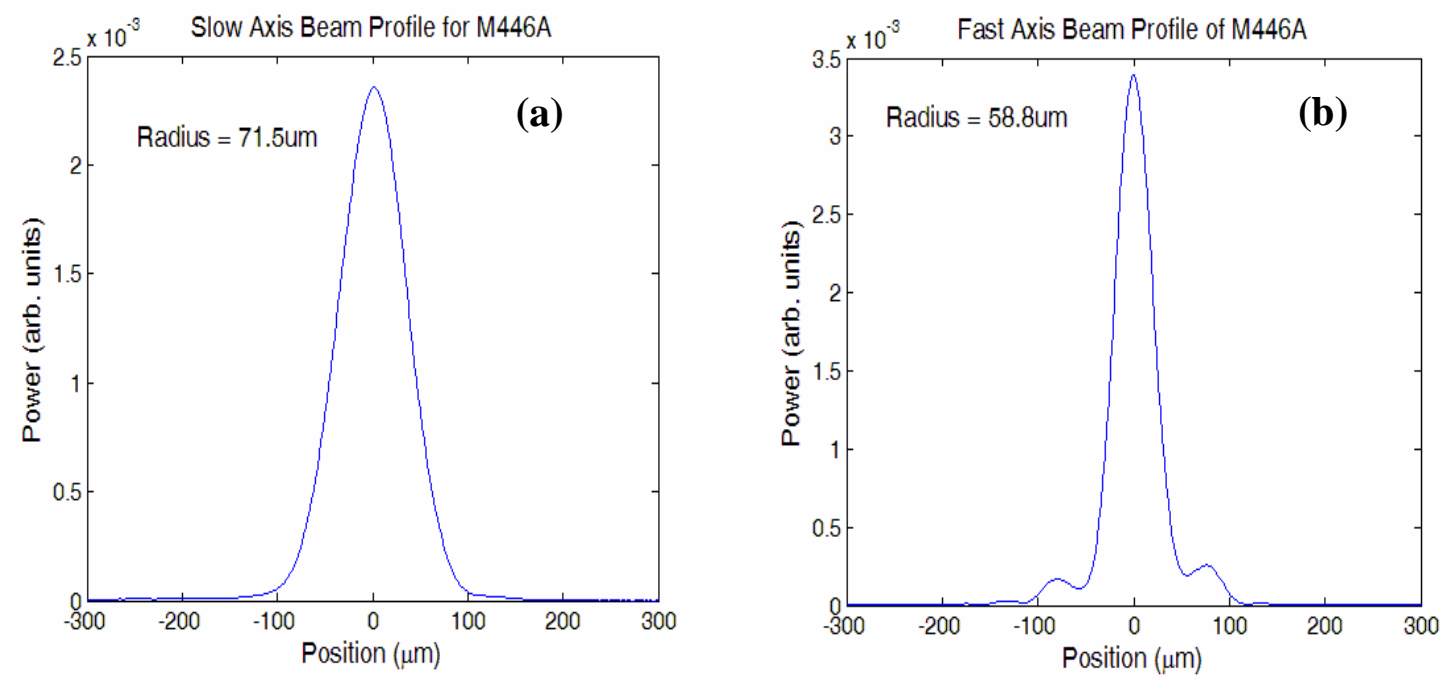

Figure 6.9. Spot Size Data Measured at Focus for (a) Slow Axis and (b) Fast Axis. The spot sizes were measured using the second moment method with a $1 \%$ clip level. 


\subsection{Summary}

During FY 2006, PNNL's Infrared Photonics research team made measurable progress exploiting the extraordinary optical and material properties of chalcogenide glass to develop miniaturized integrated photonic components. The culmination of this development effort led to the first reported demonstrated of a MWIR single-mode waveguide in chalcogenide glass coupled to a QCL source. Traditional and direct-write lithography processes were developed for chalcogenide glass that will provide the capability to fabricate etched ridge waveguides structures with index modulation provide by direct-laser written Bragg grating structures. The successful development of these capabilities open up many possibilities specifically in the development of waveguide beam combiners, splitters, and resonant wavelength locking cavities - that will be an integral component within the QCL transmitter design.

Several improvements were made to the chalcogenide glass thin film deposition system, including the installation of a 192 square foot, Class 10,000 clean room. It is anticipated that these improvements will lead to the routine production of low-loss, optical quality chalcogenide thin films required for the photonic component development effort. Additionally, chalcogenide optical fiber processing methods are being developed using a Vytran large core optical fiber fusion splicer. This work will provide PNNL with a unique capability to process infrared optical fibers to produce tapered QCL laser couplers, fiber splitters and combiners, and fiber-to-fiber fusion splicing.

Custom asphere lens designs were developed to efficiently collect the highly divergent QCL emission and refocus into both chalcogenide optical fibers and thin-film waveguides. These lenses were sent offsite for fabrication using single-point diamond turning methods and then characterized using the suite of LWIR optical metrology tools developed at PNNL.

The Infrared Photonics research is positioned to develop chalcogenide-based infrared photonic components such as waveguides, beam splitters, multiplexers, couplers, beam shapers, Bragg reflectors, long-period gratings, hybrid lenses, and optical fibers. The integration of these photonic components and optical fibers along with the QCL source will provide a compact laser transmitter, meeting the needs for a variety of infrared sensing missions. 


\subsection{References}

Anheier NC, BR Johnson and SK Sundaram. 2004. "Laser writing in arsenic trisulphide glass," in Optoelectronic Materials and Devices Volume 1, 2004, Non-Crystalline Materials for Optoelectronics. ed. G Lucovsky and M Popescu, INOI Publishing, Bucharest.

Anheier NC, et al. 2005. FY2005 Infrared Photonics Final report. PNNL-15581. Pacific Northwest National Laboratory, Richland, Washington.

Bryce RM, HT Nguyen, P Nakeeran, RG DeCorby, PK Dwivedi, CJ Haugen, JN McMullin and SO Kasap. 2004. "Direct UV patterning of waveguide devices in As2Se3 thin films," J. Vac. Sci. Tech. A 22, 1044-1047.

Hitz B. 2006. "Planar waveguide transmits mid-infrared radiation," Photonics Spectra, Vol. 40, 102-104.

Hô N, M Phillips, H Qiao, P Allen, K Krishnaswami, B Riley, T Myers and N Anheier. 2006a. "Singlemode low-loss chalcogenide glass photonic components for mid-infrared operations," Frontier in Optics 2006, JWD88.

Hô N, M Phillips, H Qiao, P Allen, K Krishnaswami, B Riley, T Myers and N Anheier. 2006b. "Singlemode low-loss chalcogenide glass waveguides for the mid-infrared," Optics Letters 31(12), 1860-1862.

Hofstetter D, et al. 2001. "Continuous wave operation of $9.3 \mu \mathrm{m}$ quantum cascade laser on Peltier cooler,” Appl. Phys. Lett., 78, 1964-1966.

Kobolov AV and K Tanaka. 2001. "Photoinduced phenomena in amoprphous chalcogenides: from phenomenology to nanoscale," Handbook of Advanced Electronic and Photonic Materials and Devices, ed. HS Nalwa, Academic Press.

Krishnaswami K, B Krejca, SR Vangala, C Santeufemio, LP Allen, M Ospina, X Liu, C Sung, K Vaccaro and WD Goodhue. 2004. "Determination of nano fluctuations in surface oxides of GaSb with Br-IBAE," Mat. Res. Symp. Proc., Vol. 786, 329-334.

Liu ZJ, et al. 2006. "Room-temperature continuous wave quantum cascade lasers grown by MOCVD without lateral regrowth," IEEE Photon. Technol. Lett., 18, 1347-1349.

Mansuripur M and EM Wright. 2002. "The optics of semiconductor diode lasers," Optics and Photonics News, 13(7), 57-61.

Ponnampalam N, RG DeCorby, HT Nguyen, PK Dwivedi, CJ Haugen, JN McMullin and SO Kasap. 2004. "Small core rib waveguides with embedded gratings in As2Se3 glass," Optics Express.

Siegman AE. 1993. "Analysis of laser beam quality degradation caused by quartic phase aberrations," Appl. Opt., 32(30), 5893-5901. 
Siegman AE. 1998. "How to (maybe) measure laser beam quality," in DPSS Lasers: Applications and Issues, OSA TOPS, 17.

Welford WT. 1986. Aberrations of Optical Systems. Adam Hilger, Boston. 



\section{Distribution}

No. of

\section{Copies}

\section{OFFSITE}

Mr. W. Randy Bell

United States DOE

NNSA/NA-22

1000 Independence Ave. SW

Washington, DC 20585

Dr. David Berry

United States DOE

NNSA/NA-22

1000 Independence Ave. SW

Washington, DC 20585

LTC Ariel Cuadrado

United States DOE

NNSA/NA-22

1000 Independence Ave. SW

Washington, DC 20585

Dr. Victoria T. Franques

United States DOE

NNSA/NA-22

1000 Independence Ave. SW

Washington, DC 20585

Mr. Ralph Hastings

United States DOE

NNSA/NA-22

1000 Independence Ave. SW

Washington, DC 20585

Mr. Eric Sanders

United States DOE

NNSA/NA-22

1000 Independence Ave. SW

Washington, DC 20585
No. of

Copies

Dr. Vaughn Standley

United States DOE

NNSA/NA-22

1000 Independence Ave. SW

Washington, DC 20585

Professor Henryk Temkin

Program Manager

DARPA/MTO

3701 N. Fairfax Dr.

Arlington, VA 22203-1714

Dr. Rhys M. Williams

United States DOE

NNSA/NA-22

1000 Independence Ave. SW

Washington, DC 20585

\section{ONSITE}

\section{Pacific Northwest National Laboratory}

Allen, PJ

K5-25

Anheier, NC (4)

K5-25

Bernacki, BE

K5-25

Bruckner-Lea, $\mathrm{C}$

$\mathrm{K} 5-25$

Clemmer, RG

$\mathrm{K} 8-02$

Dudder, GB

$\mathrm{K} 8-29$

Hô, N

K5-25

Krishnaswami, $\mathrm{K}$

$\mathrm{K} 5-25$

Schultz, JF (10)

$\mathrm{K} 5-25$

Sharpe, SW

$\mathrm{K} 8-88$

Qiao, A

K5-20

Information Release Office (7)

K1-06 